\title{
The Neuropeptide Pigment-Dispersing Factor Adjusts Period and Phase of Drosophila's Clock
}

\author{
Taishi Yoshii, ${ }^{1}$ Corinna Wülbeck, ${ }^{1}$ Hana Sehadova, ${ }^{2}$ Shobi Veleri, ${ }^{1}$ Dominik Bichler, ${ }^{1}$ Ralf Stanewsky,,${ }^{1,2}$ and \\ Charlotte Helfrich-Förster ${ }^{1}$ \\ ${ }^{1}$ Institute of Zoology, University of Regensburg, 93040 Regensburg, Germany, and ${ }^{2}$ School of Biological and Chemical Sciences, Queen Mary University, \\ London E1 4NS, United Kingdom
}

The neuropeptide pigment-dispersing factor (PDF) is a key transmitter in the circadian clock of Drosophila melanogaster. PDF is necessary for robust activity rhythms and is thought to couple the circadian oscillations of the clock neurons. However, little is known about the action of PDF on individual clock neurons. Here, we combined the period-luciferase reporter system with immunolabeling of clock proteins in wild-type and $P d f^{\rho 1}$ mutants to dissect the effects of PDF on specific subgroups of clock neurons. Additionally, PDF levels were elevated to higher than normal levels using specific neural mutants, and a correlation analysis of locomotor activity and clock protein staining served to determine the periods of specific clock cells. We found that PDF has multiple effects on the clock neurons: In some groups of clock neurons, PDF was required for maintaining the oscillations of individual cells, and in others, PDF was required for synchronous cycling of the individual members. Other clock neurons cycled with high amplitude in absence of PDF, but PDF affected their intrinsic clock speed. Sometimes PDF shortened and sometimes PDF lengthened period. Our observations indicate that PDF is crucial for adjusting cycling amplitude, period, and phase of the different players in the circadian clock. Under natural conditions PDF may be required for adapting Drosophila's clock to varying photoperiods. Indeed, we show here that $P d f^{01}$ mutants are not able to adapt their activity to long photoperiods in a wild-type manner.

Key words: pigment-dispersing factor; period; timeless; internal desynchronization; circadian rhythms; neuropeptide

\section{Introduction}

Animals possess endogenous clocks in the brain that coordinate behavioral and physiological rhythms and help to adapt to the $24 \mathrm{~h}$ day/night cycle on earth. These clocks consist of numerous neurons that have the capability to oscillate with periods close to $24 \mathrm{~h}$ because of molecular feedback loops generated by the interaction of highly conserved clock genes and proteins (Lowrey and Takahashi, 2004; Hardin, 2005). As signaling molecules, animal clocks use neuropeptides that synchronize the oscillations of individual clock neurons and transfer circadian signals to downstream neurons (Maywood et al., 2006; Nässel and Homberg, 2006). In mammals, the vasoactive intestinal polypeptide (VIP) fulfils this role and is essential for normal behavioral rhythmicity (Aton et al., 2005; Vosko et al., 2007). A similar role has been proposed for the pigment-dispersing factor (PDF) in insects

Received Nov. 11, 2008; revised Jan. 12, 2009; accepted Jan. 12, 2009.

This work was supported by Deutsche Forschungs Gemeinschaft Grants F0207/9-1,2 (C.H.-F.) and Sta421/4 and Sta421/5 (R.S.); the Graduate College 640; and EUCLOCK. We thank A. Hofbauer for the nb33 monoclonal antibody, I. Edery for the TIM antiserum, T. Todo for the CRY antiserum, K.-F. Fischbach for the $s 0^{7}$ mutants, J. C. Hall for the so ${ }^{m d a}$ mutants, P. Taghert for the PdP ${ }^{01}$ mutants, A. Hofbauer, and 0 . Shafer for comments on this manuscript, as well as members of our laboratories for fruitful discussions. We are very grateful to Olympus UK Ltd., namely to Alan Kidger and Werner Kammerloher for generously providing Lumnoview LV200.

Correspondence should be addressed to Charlotte Helfrich-Förster, Institute of Zoology, University of Regensburg, Universitaetsstrasse 31, 93040 Regensburg, Germany. E-mail: charlotte.foerster@biologie.uni-regensburg.de.

S. Veleri's present address: Laboratory of Molecular Biology, Porter Neuroscience Research Center, Bethesda, MD 20892-3736.

DOI:10.1523/JNEUROSCI.5439-08.2009

Copyright $\odot 2009$ Society for Neuroscience $\quad$ 0270-6474/09/292597-14\$15.00/0
(Renn et al., 1999; Peng et al., 2003; Lin et al., 2004; Schneider and Stengl, 2005; Nitabach et al., 2006). Both, VIP and PDF work via closely related G-protein-coupled receptors of the B1 subfamily (classical hormone receptor) that are present on the clock neurons themselves (Hyun et al., 2005; Lear et al., 2005; Mertens et al., 2005; Shafer et al., 2008). Thus, VIP and PDF may couple the oscillations of individual cells as was recently shown for PDF regarding ultradian oscillations in membrane potential within the cockroach clock (Schneider and Stengl, 2005).

In Drosophila, $P d f$-null mutants $\left(P d f^{01}\right)$ are arrhythmic or show weak behavioral rhythms with short period (Renn et al., 1999). On the molecular level, individual clock neurons seem to remain rhythmic and to cycle with short period (Wu et al., 2008), and in certain groups of clock cells, the oscillations lose synchrony (Peng et al., 2003; Klarsfeld et al., 2004; Lin et al., 2004). The common hypothesis is that PDF feeds back on the oscillations of individual neurons, lengthens their period, and additionally synchronizes their oscillations.

However, a recent study suggests that the role of PDF is more complex (Wülbeck et al., 2008). When PDF is increased to higher than normal levels, short- and long-period components appeared in the activity pattern. This suggests that PDF not only has period-lengthening effects but also shortens the period of certain clock neurons in a dose-dependent manner (Wülbeck et al., 2008). However, the identity of these neurons remained unknown.

Here, we identify the neurons that respond with period short- 
ening to excessive PDF. Furthermore, we show for the first time that PDF has different effects on the period of the different clock neurons even in wild-type flies. Under natural conditions, this property of PDF might keep the oscillations in the different subsets of clock neurons slightly out of phase. Such a multiphasic clock organization was also found in the mammalian clock (Quintero et al., 2003; Yamaguchi et al., 2003) and proposed to account for many properties of circadian organization as the response to seasonal variations in the photoperiod by altering the coupling of its constituent oscillators (Pittendrigh and Daan, 1976). PDF seems to be critically involved in these processes.

\section{Materials and Methods}

Fly rearing and strains. Flies were reared on cornmeal/agar medium supplemented with yeast and kept in a temperature-constant room at $20^{\circ} \mathrm{C}$ and in a light/dark cycle with $12 \mathrm{~h}$ light and $12 \mathrm{~h}$ darkness (LD 12:12). The lab strain CantonS was used as wild-type control. $P d f^{01}$ mutants $\left(w^{+}\right.$; $P d f^{01}$ ) carry a point mutation in the part of the $P d f$-gene that codes for the PAP-precursor of $P d f$ and lack PDF completely (Renn et al., 1999).

The period-luciferase strain 8.0-luc:9 that expresses the luciferase only in subsets of the pacemaker neurons was used as real-time reporter for oscillations of the clock gene period (Veleri et al., 2003). Furthermore, a stable 8.0-luc:9;Pdf ${ }^{01}$ line was generated to monitor the molecular oscillations in the absence of PDF. Both strains carried an X chromosome marked with $y w$, resulting in white eye and yellow body color. To see in which clock neurons the per 8.0-luc:9 transgene is expressed, we brought the 8.0-luc:9 and 8.0-luc:9;Pdf ${ }^{01}$ lines in the per ${ }^{01}$ background and performed immunostainings with an antibody against the Period protein (PER) (see below) (Veleri et al., 2003).

To increase PDF levels in the central brain, the following optic lobe affecting mutants were used: sine oculis ${ }^{1}\left(\right.$ so $\left.^{1}\right)$ and sine oculis ${ }^{\text {medusa }}$ $\left(s o^{m d a}\right)$. The phenotype of these mutants including their rhythmic behavior is described in detail by Wülbeck et al. (2008). Briefly, adult so ${ }^{1}$ flies have optic lobes that are reduced to $20 \%$ of its normal volume (Fischbach, 1983), whereas the optic lobes of $s 0^{\text {mda }}$ mutants have $<5 \%$ of normal size (Wülbeck et al., 2008). As a consequence, both mutations affect the arborizations of a subgroup of the clock neurons, the PDFpositive large ventral lateral neurons $\left(1-\mathrm{LN}_{\mathrm{v}}\right)$ (see Fig. 1). The $1-\mathrm{LN}_{\mathrm{v}}$ arborize in the most distal layer of the medulla putatively transferring circadian signals to the optic lobes (eyes) (Helfrich-Förster, 1997). In addition, they connect the pacemaker centers, the accessory medullae $(\mathrm{aMe})$, of both brain hemispheres via fibers in the posterior optic tract (see Fig. 1) (Helfrich-Förster et al., 2007a). In the mutants, the size of the medulla is reduced and the $1-\mathrm{LN}_{\mathrm{v}}$ cells project into the central brain instead of arborizing on the surface of the medulla. This leads to increasing amounts of PDF fibers in the aMe and the dorsal protocerebrum that may release high amounts of PDF into these areas and provoke alterations in the activity rhythms (Wülbeck et al., 2008). so ${ }^{I}$ mutants show a higher density of PDF fibers in the aMe and exhibit significantly longer periods $(24.6 \mathrm{~h})$ than wild-type flies (Table 1$)$. When PDF was absent $\left(s o^{1} ; P d f^{01}\right.$ double mutants), the period came back to the short value of $P d f^{01}$ showing that the period lengthening is caused by PDF (Table 1). $s o^{m d a}$ mutants show additionally many more PDF fibers in the dorsal brain than $s o^{1}$ mutants and in the activity rhythm a short-period component $(21.3 \mathrm{~h})$ split off the long $(24.7 \mathrm{~h})$ period (Table 1$)$. This short period was significantly shorter than the short period of flies that lack PDF (Pdf $f^{01}, s 0^{1} ; P d f^{11}$, and $s o^{m d a} ; P d f^{01}$ mutants), indicating that PDF shortens the period of certain clock neurons in addition to lengthening that of others.

Luciferase monitoring. Luciferase expression of individual flies carrying the 8.0-luc transgene was measured as described by Veleri et al. (2003). Before each experiment, flies were entrained for at least $3 \mathrm{~d}$ to a LD 12:12 and kept in the same regimen for the first day of the experiment. Subsequently the lights were turned off and the flies were monitored for $6 \mathrm{~d}$ in constant darkness (DD). Raw data were plotted and analyzed with Import and Analysis software (Plautz et al., 1997). For details, see Veleri et al. (2003).

To visualize the neurons in which luciferase was expressed, flies were entrained for $5 \mathrm{~d}$ to a LD 12:12. Four hours after lights-on, male brains were dissected under M3 Insect Medium (Sigma-Aldrich) and kept in culture medium [M3 Insect Medium with fetal bovine serum, penicillinstreptomycin, insulin, and luciferin $(200 \mu \mathrm{M}$; Biosynth)]. Four hours after lights-off, the samples were imaged in the Luminoview LV200 (Olympus). Brains were exposed for $40 \mathrm{~min}$ at a gain of 255 . The bioluminescence intensity was shown in pseudocolors after background subtraction using Rainbow3 (Cell M; Olympus).

Immunohistochemistry for determination of PER-, TIM-, CRY-, and PDF-positive neurons in per $^{0}$;per-luc flies. Flies were quickly killed by submersion in $4 \%$ freshly prepared paraformaldehyde in phosphate buffer (PB) with $0.5 \%$ Triton $\mathrm{X}$, shortly before lights-on, when PER and Timeless (TIM) levels are high. After $2 \mathrm{~h}$ fixation, the flies were rinsed three times for $15 \mathrm{~min}$ in $\mathrm{PB}$, and their brains were dissected as whole mounts. Then fluorescent immunohistochemistry was applied as described previously (Rieger et al., 2006). The primary antisera were as follows: rat anti-TIM serum (diluted 1:1000) (Sidote et al., 1998), rabbit anti-cryptochrome (CRY) serum (Yoshii et al., 2008), or rabbit anti-PER serum (diluted 1:1000) (Stanewsky et al., 1997), and the monoclonal mouse antibody nb33 (diluted 1:100). The latter is directed against the PDF precursor and thus recognizes the PDF-positive neurons (Veleri et al., 2003). The secondary antisera were as follows: Alexa 488 (goat antirabbit), Alexa 568 (goat anti-rat), and Alexa 647 (goat anti-mouse), all diluted 1:200 (Invitrogen). The immunofluorescent brains were embedded in Vectashield mounting medium (Vector Laboratories), directly after rinsing in $\mathrm{PB}$.

Triple labeling (green channel, PER or CRY; red channel converted to magenta, TIM; infrared channel converted to yellow, PDF) was visualized by laser-scanning confocal microscopy (Zeiss LSM 510 META; Carl Zeiss MicroImaging). Confocal stacks of $2 \mu \mathrm{m}$ thickness were obtained at intervals of $2.4 \mu \mathrm{m}$ and overlaid (using the LSM Meta software; version 3.2.0.99) to visualize the lateral neurons in the anterior brain and the dorsal neurons in the posterior brain. To exclude bleed-through, we used sequential scans of the three laser lines.

Activity recording. At the age of 1-3 d, individual male flies were transferred into the recording chambers. Locomotor activity was recorded photoelectrically at $20^{\circ} \mathrm{C}$ as described previously (Helfrich-Förster, 1998). Halogen photooptic lamps (Osram; XENOPHOTR) served as a light source and intensity was adjusted to $500 \mu \mathrm{W} / \mathrm{cm}^{2}$ with a dimmer. For judging the free-running locomotor rhythm, activity was recorded for up to $7 \mathrm{~d}$ under LD 12:12, and then the flies were transferred to DD. The raw data were displayed as actograms (double plots) to judge the activity pattern, and the periods under DD were determined by the Sokolove-Bushell periodogram analysis (program El Temps, version 1, 226; Antoni Díez-Noguera, Barcelona, Spain).

For judging the activity pattern under different photoperiods, wildtype and $P d f^{01}$ flies were recorded for 1 week, respectively, under the following day/night lengths: $8: 16$ h, 12:12 h, 16:8 h, 20:4 h. Light intensity was adjusted to 100 lux during the day and to 0.03 lux during the night. The dim light during the night prevented the flies from being completely 
inactive at night. Average activity profiles were calculated for each photoperiod, and the mean phases of morning and evening peaks were calculated as described previously (Rieger et al., 2003).

Immunohistochemistry for determination of PER or TIM staining intensity. To judge the state of the molecular clock in the different clock neurons during the first $5 \mathrm{~d}$ in DD, wild-type flies and $P d f^{01}$ mutants were collected at circadian time 11 (CT11) and CT23. The circadian times of each strain were calculated by average free-running periods of each strain in DD (24.2 h for wild-type flies and $22.8 \mathrm{~h}$ for $P d f^{\rho 1}$ mutants) (Table 1). The collected samples of wild-type flies and $P d f^{01}$ mutants were subjected to TIM, CRY, and PDF triple immunohistochemistry as described above. Ten brains were stained per time point.

To judge the state of the molecular clock in $s o^{1}$ and $s o^{m d a}$ flies after several days in DD, $10 s o^{l}$ and $10 s o^{m d a}$ flies, respectively, were collected at two different time points in DD. For $s o^{1}$ flies, these times were (1) the subjective early morning, just before they became active, and (2) the subjective evening, when they were maximally active on the third to fourth day in DD (see Fig. 5, red and blue points). For $s o^{m d a}$ flies, these times were (1) during the activity peak of the component free-running with short period and (2) during the activity peak of the component free-running with long period on the third to fourth day in DD (see Fig. 5 , red and blue points). Furthermore, some $s o^{m d a}$ flies were stained on the sixth day in DD, when both components were again in phase, at the times of low and high activity.

All brains were subjected to TIM, CRY, and PDF triple immunohistochemistry (see above). One experiment was additionally performed with TIM, PER, and PDF triple immunohistochemistry.

Scoring of staining intensities was performed on single optical sections as described by Rieger et al. (2006), but with the following modifications. Each neuron within each group was assessed separately. If there was no staining in one or more neurons of a given group, these neurons were assigned to have background staining levels. The background staining level was measured in the surrounding field of each neuronal group and subtracted from the pixel intensities measured for the cells. A mean staining intensity was calculated from all neurons within one group for each hemisphere separately. Then for each group an average staining intensity per brain was calculated out of the staining intensities of both hemispheres.

Statistics. Staining intensities were tested for normal distribution using the Lillifors test. For testing for significant influences of strain and time on PER and TIM stainings in the clock neurons, a two-way ANOVA was applied. In both cases, a subsequent post hoc (Bonferroni adjustment) served for pairwise comparisons of staining intensities. Values were regarded as significantly different at $p<0.05$.

\section{Results}

Figure 1 gives an overview of Drosophila's clock neurons. PDF is expressed in the small and large ventral lateral neurons $\left(s-\mathrm{LN}_{\mathrm{v}}\right.$ and $1-\mathrm{LN}_{\mathrm{v}}$ ). Both types of neurons arborize in the aMe, which seems to represent the main pacemaker center of the fly. The $s-\mathrm{LN}_{\mathrm{v}}$ cells project additionally into the dorsal brain, a brain area that comprises additional clock neurons, the dorsal neurons $\left(\mathrm{DN}_{1}, \mathrm{DN}_{2}\right.$, and $\left.\mathrm{DN}_{3}\right)$. The s- $\mathrm{LN}_{\mathrm{v}}$ cells appear to release PDF rhythmically into this area (Park et al., 2000). There is evidence that the s- $\mathrm{LN}_{\mathrm{v}}$ cells are the most important clock neurons for rhythmic behavior in DD (Helfrich-Förster, 2005; Stoleru et al., 2005; Picot et al., 2007). There is a fifth PDF-negative s- $\mathrm{LN}_{\mathrm{v}}$ that is typically located among the $1-\mathrm{LN}_{\mathrm{v}}$ cells and that seems to have the same arborization patterns as the PDF-positive s- $\mathrm{LN}_{\mathrm{v}}$ cells and to play a similar crucial role in the circadian clock (Rieger et al., 2006; Helfrich-Förster et al., 2007b). Slightly dorsal of the s- $\mathrm{LN}_{\mathrm{v}}$ and $\mathrm{l}-\mathrm{LN}_{\mathrm{v}}$ lie the dorsal lateral neurons $\left(\mathrm{LN}_{\mathrm{d}}\right)$ that connect to the aMe and the dorsal brain as do most of the DN cells (Shafer et al., 2006; Helfrich-Förster et al., 2007a). For better clarity, all these connections except those of the PDF neurons are omitted in Figure 1. The described groups of clock cells can be further subdivided in CRY-positive and CRY-negative cells (Fig. 1) (Yoshii

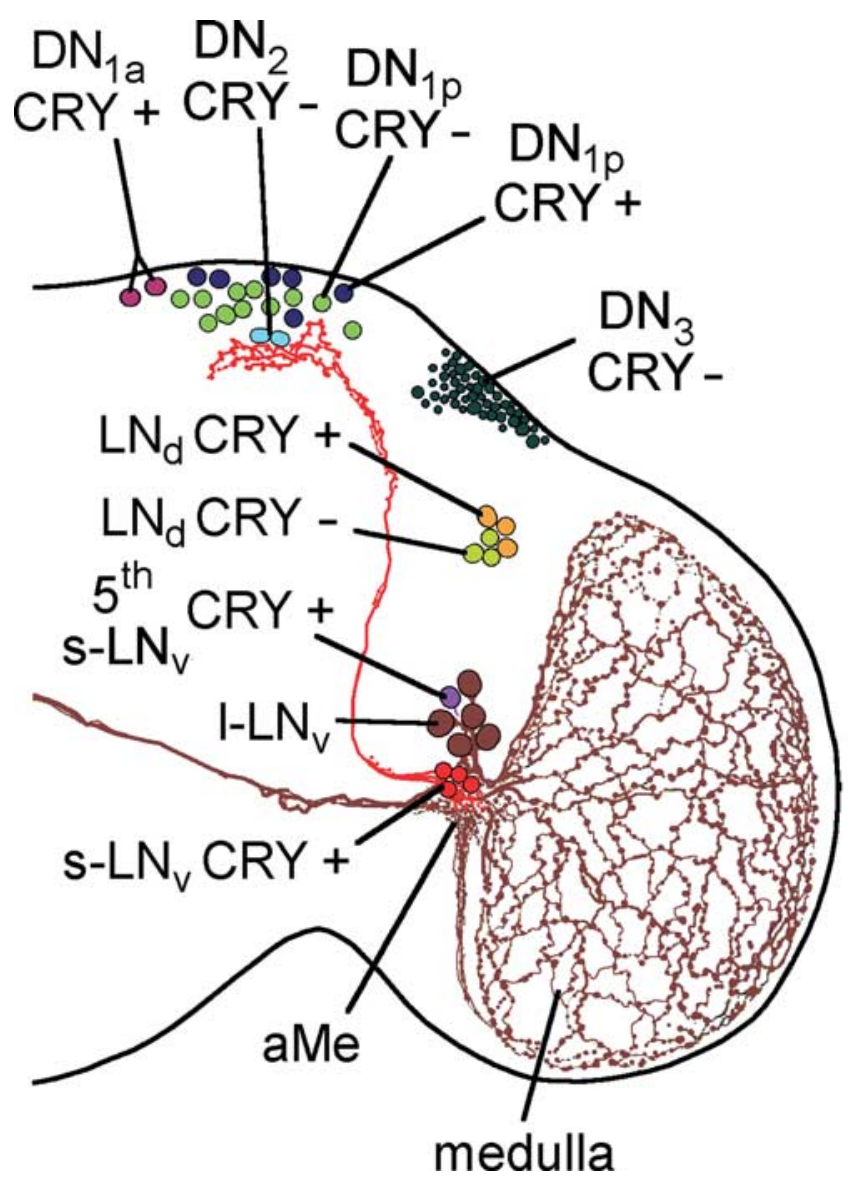

Figure 1. Circadian clock neurons in the right brain hemisphere of the fruit fly. PDF is expressed in two groups of the lateral neurons, the $-\mathrm{LN}_{v}$ and $s-\mathrm{LN}_{v}$. Of these neurons, the arborization patterns are shown; all others are omitted for clarity. The fifth PDF-negative $s-\mathrm{LN}_{v}$ is located among the I- $\mathrm{LN}_{\mathrm{v}}$, and the $\mathrm{LN}_{\mathrm{d}}$ are located dorsally of the $\mathrm{I}-\mathrm{LN}_{\mathrm{v}}$. Whereas all s-LN $\mathrm{LN}$ and I-LN $\mathrm{LN}$ cells contain CRY, only three of the six $\mathrm{LN}_{\mathrm{d}}$ are CRY-positive. The dorsal neurons in the posterior dorsal brain were traditionally divided in three groups $\left(\mathrm{DN}_{1}, \mathrm{DN}_{2}\right.$, and $\left.\mathrm{DN}_{3}\right)$, but they seem to be composed of heterologous cells. Among the $\mathrm{DN}_{1}$, two cells are located in more anterior regions and are therefore called $\mathrm{DN}_{\text {1anterior }}\left(\mathrm{DN}_{1 \mathrm{a}}\right)$, whereas the other up to $15 \mathrm{DN}_{1}$ are called $\mathrm{DN}_{1 \text { posterior }}$ $\left(\mathrm{DN}_{1 \mathrm{p}}\right)$. The $\mathrm{DN}_{1 \mathrm{a}}$ and six of the $\mathrm{DN}_{1 \mathrm{p}}$ cells are CRY-positive. The two $\mathrm{DN}_{2}$ cells are located close to the $s$ - $\mathrm{LN}_{\mathrm{v}}$ terminals and both are $\mathrm{CRY}$-negative. The $\mathrm{DN}_{3}$ consist of $\sim 40$ neurons of predominantly small size that are all CRY-negative; but there are few larger neurons among them that might have different properties.

et al., 2008). The PDF receptor is most likely expressed in all clock neurons except the $1-\mathrm{LN}_{\mathrm{v}}$ cells (Shafer et al., 2008).

Our aim was to elucidate how PDF influences the molecular PER/TIM oscillations in the different groups of clock neurons.

Pdf $^{01}$ mutants show sustained per-luciferase oscillations with short period, whereas these oscillations dampen in wild-type flies

In a first step, we monitored the molecular oscillations in the clock neurons in vivo using the luciferase based real-time reporter assay described previously (Veleri et al., 2003). To specifically reveal the molecular oscillations in certain groups of the clock neurons, we used flies carrying the period-luciferase construct 8.0-luc:9, which is restricted to the dorsal neurons $\left(\mathrm{DN}_{1}-\mathrm{DN}_{3}\right)$ and few dorsal lateral neurons $\left(\mathrm{LN}_{\mathrm{d}}\right)$ (Veleri et al., 2003). The construct was inserted in wild-type and $P d f^{01}$ flies (both in the $y w$ background), and the activity rhythm of the transgenic flies was tested to make sure that the construct did not affect behavior. We found that the $y w ; 8.0$-luc:9 flies showed wild-type rhythms with 

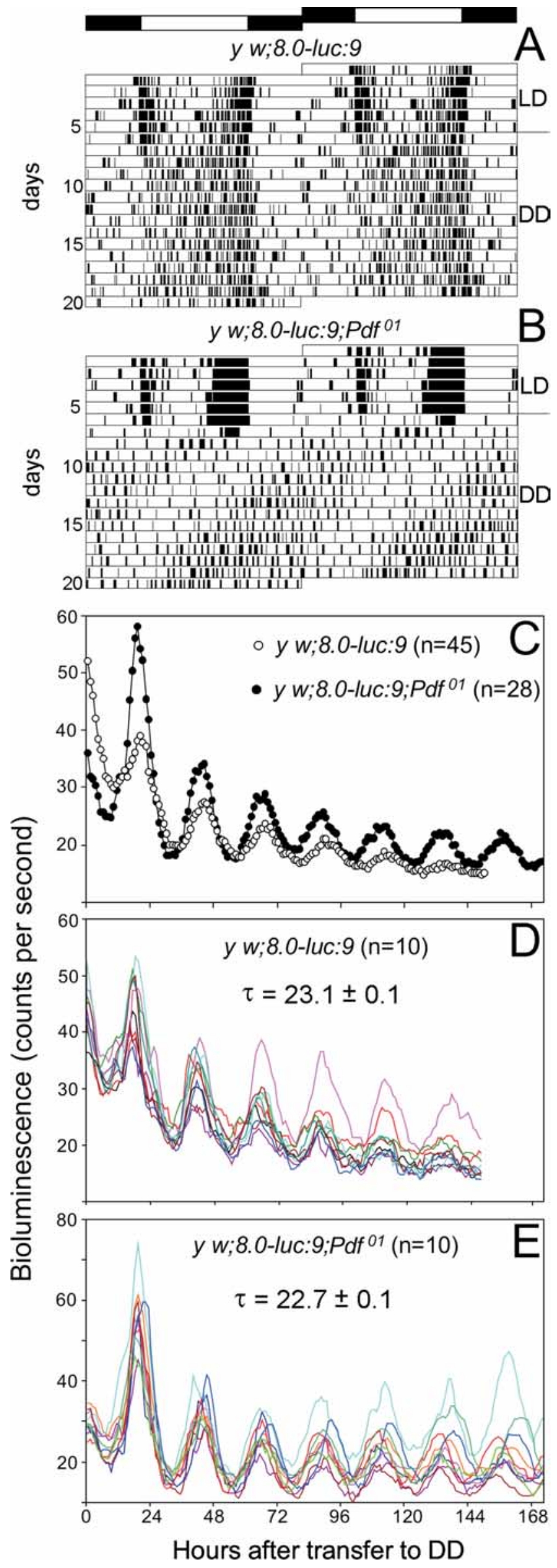

endogenous behavioral periods close to $24 \mathrm{~h}$ (Fig. $2 \mathrm{~A}$, Table 1), whereas $y$ w;8.0-luc:9;Pdf $f^{01}$ flies behaved like $P d f^{01}$ mutants exhibiting, if rhythmic at all, weak rhythmicity with a period of 22.8 h (Fig. $2 B$, Table 1 ).

In $y$; $8.0-$-luc:9 flies, the luciferase-based real-time reporter assay revealed that PER protein oscillations in the $\mathrm{DN}$ and $\mathrm{LN}_{\mathrm{d}}$ cells continued for $6 \mathrm{~d}$ in constant darkness, although with a dampening amplitude (Fig. 2C,D) (cf. Veleri et al., 2003). Obviously, the per cycling in the luciferase-expressing clock neurons remained more or less in synchrony for several days in DD. This is in ultimate contrast to the per-luciferase cycling in peripheral tissues and organs that became asynchronous shortly after transfer into DD and speaks for a synchronizing factor present in the brain (Veleri et al., 2003). PDF could be this synchronizing agent between the brain clock neurons. Therefore, we expected the per-luciferase oscillations to be more dampened in the $P d f^{01}$ background.

To our surprise, these oscillations were even less dampened in $y$ w;8.0-luc:9;Pdf $f^{01}$ mutants. They continued with high amplitude for $>6 \mathrm{~d}$ in constant darkness (Fig. $2 C, E$ ). This confirms previous results obtained with disco $^{2} ; 8.0-l u c: 9$ flies that lack all LNs and are therefore also PDF-null (Veleri et al., 2003) and indicates that the luciferase-positive cells oscillate rather synchronously in the absence of PDF. Obviously, PDF is not needed as synchronizing agent and its presence even provokes a slight asynchrony among these neurons. Most interestingly, the luciferase rhythm of $P d f^{01}$ had a period of $22.7 \mathrm{~h}$ that does nicely correspond to the weak $22.8 \mathrm{~h}$ period that $P d f^{01}$ mutants display in the activity rhythm (Table 1, Fig. $2 B$ ). This suggests that the $\mathrm{DN}$ and $\mathrm{LN}_{\mathrm{d}}$ cells are responsible for the short-period rhythm observed in some $P d f^{01}$ mutants. Nevertheless, the behavioral rhythms of $P d f^{01}$ mutants were very weak, showing that the short-period oscillations in the $\mathrm{DN}$ and $\mathrm{LN}_{\mathrm{d}}$ cells are not sufficient for strong rhythmicity in DD, a postulation that was already made by previous studies (Blanchardon et al., 2001; Veleri et al., 2003; Stoleru et al., 2005). That the $\mathrm{DN}$ and $\mathrm{LN}_{\mathrm{d}}$ are not the main neurons controlling behavioral rhythmicity in DD becomes also evident from the data gained for wild-type flies (Fig. $2 A, D$ ), which showed rather robust behavioral rhythms with periods around $24 \mathrm{~h}$ (Table 1), whereas the per-luciferase oscillations in the $\mathrm{DN}$ and $\mathrm{LN}_{\mathrm{d}}$ had a significantly shorter period (23.1 h) and were dampened (Fig. 2D). As mentioned, the most important clock neurons for rhythmicity under DD conditions are the s- $\mathrm{LN}_{\mathrm{v}}$ cells, and these do not express the luciferase in 8.0-luc flies and do therefore not contribute to the per-luciferase rhythm (Veleri et al., 2003).

In the present experiment, we could only see the sum of per oscillations going on in the $\mathrm{DN}$ and $\mathrm{LN}_{\mathrm{d}}$; in these, PDF did not lengthen the periods to the $\sim 24$ h value observed for the behavioral rhythms; additionally PDF provoked a slight dampening of

\footnotetext{
$\leftarrow$

Figure 2. Locomotor activity and bioluminescence rhythm of flies carrying the 8.0-luc:9 transgene in the wild-type and the $P d f^{01}$ background. Control flies $(y w ; 8.0-l u c: 9)$ show a

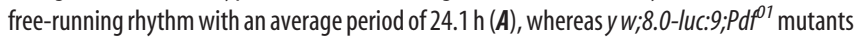
exhibit weak rhythms with an average period of $22.8 \mathrm{~h}(\boldsymbol{B})$ (compare Table 1). C, Averaged bioluminescence rhythm of 45 control flies and $28 P d f^{01}$ mutants. The flies were recorded for $6 \mathrm{~d}$ in DD after initially being entrained to three cycles of 12:12 h LD. The $y w ; 8.0-l u c: 9 ; P d P^{01}$ flies showed rather strong oscillations with a mean period of $22.7 \pm 0.1 \mathrm{~h}$, whereas y $w ; 8.0-$ luc:9 flies showed more dampened oscillations with a mean period of $23.1 \pm 0.1 \mathrm{~h}$. The weak dampening present in the $y w ; 8.0-l u c: 9 ; P d P^{p 1}$ flies is entirely attributable to slightly different free-running periods of individual flies as can be seen in $E$, in which the oscillations of individual yw;8.0-Iuc:9; PdP ${ }^{1}$ flies are shown $(n=10)$. In contrast, a dampening of the oscillations occurs already on the level of individual wild-type flies $(n=10)(\boldsymbol{D})$, indicating that the oscillating DN and $\mathrm{LN}_{\mathrm{d}}$ cells become out of phase in the presence of PDF.
} 


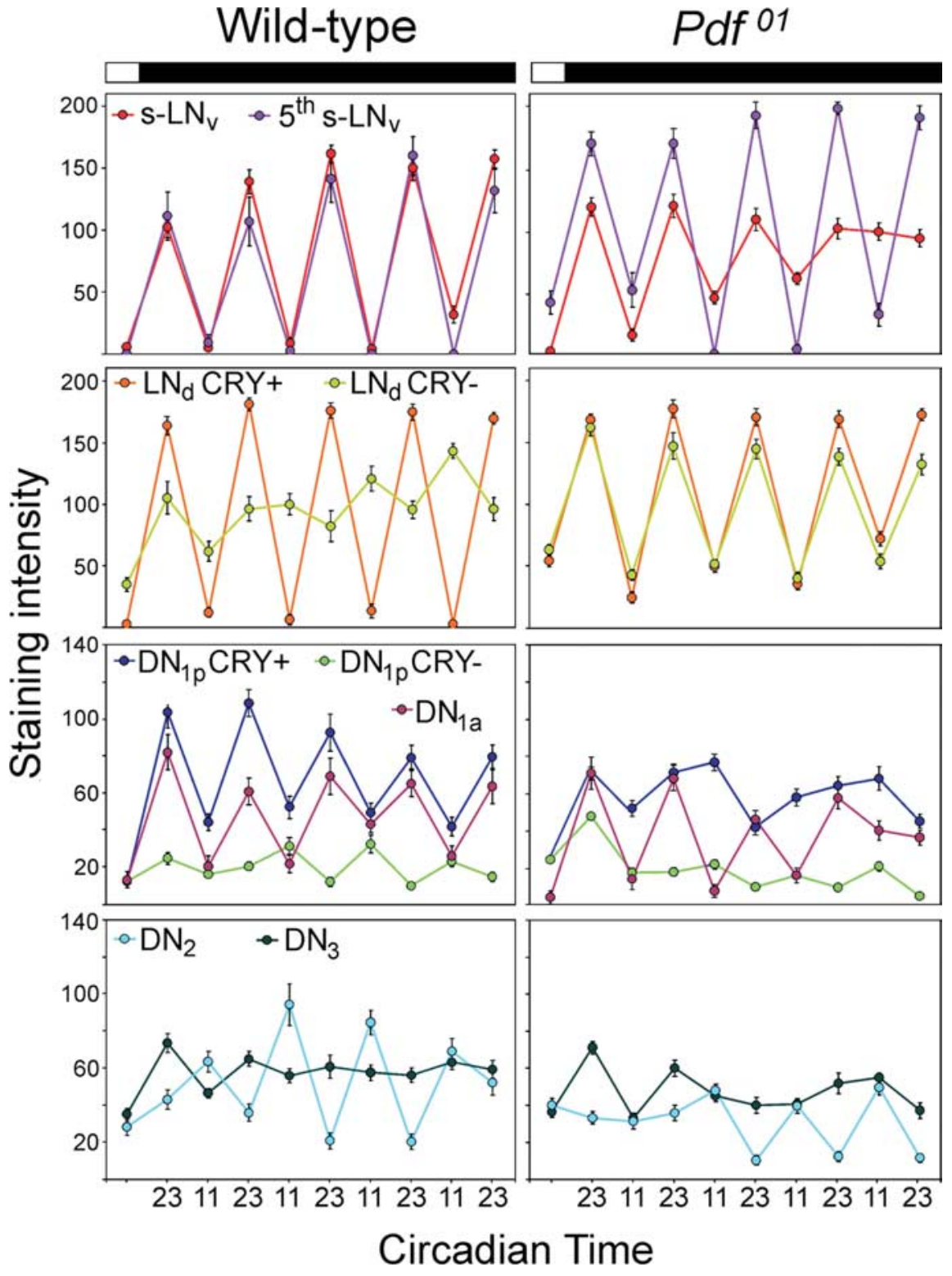

Figure 3. TIM oscillations in the different clock neurons of wild-type flies and $P d P^{01}$ mutants for $5 \mathrm{~d}$ in constant darkness. The time axis is in circadian time. Wild-type flies and $P d f^{01}$ mutants have different periods (Fig. 2); therefore, a circadian day of wild-type flies is $24.2 \mathrm{~h} \mathrm{long}$ and a circadian day of $P d f^{01}$ mutants is $22.8 \mathrm{~h} \mathrm{long}$. For both fly strains, circadian time 23 means $1 \mathrm{~h}$ before the beginning of the subjective day, and circadian time 11 means $1 \mathrm{~h}$ before the beginning of the subjective night. Usually, clock protein levels are high at circadian time 23 and low at circadian time 11. For wild-type flies, this is true for all CRY-positive neurons: the s- $\mathrm{LN}_{v}$, the fifth s- $\mathrm{LN}_{\mathrm{v}}$, three $\mathrm{LN}_{\mathrm{d}}$, the $\mathrm{DN}_{1 \mathrm{a}}$, and six DN ${ }_{1 \mathrm{p}}$ (for significances, see Table 2). However the CRY-negative $\mathrm{LN}_{\mathrm{d}}$ seem to cycle with different period and are in antiphase with the CRY-positive neurons on the fifth day in DD. The CRY-negative $\mathrm{DN}_{1 \mathrm{p}}$ and $\mathrm{DN}_{2}$ cycled in antiphase to the CRY-positive neurons already earlier, but lost their significant oscillations at the end of the

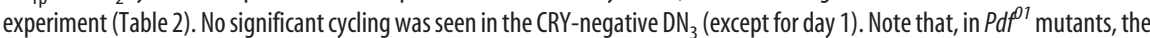
CRY-negative and CRY-positive $\mathrm{LN}_{\mathrm{d}}$ remain in synchrony with each other; the oscillations in the $s-\mathrm{LN}_{\mathrm{v}}$ and $\mathrm{DN}_{1 \mathrm{a}}$ slowly dampen, and the oscillations in the CRY-positive $\mathrm{DN}_{1 \mathrm{p}}$ disappear quickly after transfer into DD (Table 2 indicates days at which ANOVA revealed significant oscillations); for additional explanations, see text.

the oscillations. Two possible reasons for the dampening are as follows: (1) the oscillations in individual neurons stop, and (2) PDF provokes asynchrony among the individual clock neurons (e.g., by affecting the periods of individual neurons differently).

To distinguish between these possibilities, we performed immunohistochemistry with an antibody against TIM over $5 \mathrm{~d}$ in DD. TIM shows oscillations that are largely parallel to that of PER (Shafer et al., 2002); and because the anti-TIM antibody was raised in rat, we could additionally stain with anti-CRY (raised in rabbit) to distinguish the TIM cycling in CRY-positive and CRY-negative neurons (Fig. 1). We did not judge the TIM staining intensity in the l-LN $\mathrm{L}_{\mathrm{v}}$, because previous studies had shown the oscillations to stop in these neurons after transfer into DD (Yang and Sehgal, 2001; Shafer et al., 2002; Veleri et al., 2003).

\section{PDF desynchronizes the molecular oscillations of the CRY-positive and CRY-negative}

$\mathrm{LN}_{\mathrm{d}}$ samples of fly brains were stained for 5 consecutive days in DD at the putative TIM maxima and minima, respectively (Fig. 3, circadian time 23 and 11). Because wild-type flies showed an average free-running period of $24.2 \mathrm{~h}$, and $P d f^{\rho 1}$ mutant a period of $22.8 \mathrm{~h}$ (Table 1), wild-type flies have a circadian day that lasts $24.2 \mathrm{~h}$ and $P d f^{01}$ mutants one that lasts $22.8 \mathrm{~h}$, and we had to collect wild-type flies every $12.1 \mathrm{~h}$ and $P d f^{01}$ mutants every $11.4 \mathrm{~h}$ over $5 \mathrm{~d}$ in DD.

In wild-type flies, we found significant oscillations in all CRY-positive clock neurons indicating that they cycle with a $24.2 \mathrm{~h}$ period (Fig. 3, Table 2). High-amplitude cycling was present in the $4 \mathrm{~s}-\mathrm{LN}_{\mathrm{v}}$ cells and the fifth $\mathrm{s}-\mathrm{LN}_{\mathrm{v}}$ cell, whereas the $\mathrm{DN}_{1 \mathrm{a}}$ and $\mathrm{DN}_{1 \mathrm{p}}$ cells cycled with slightly lower amplitude. In contrast to the CRY-positive neurons, the CRY-negative cells showed a completely different behavior: In the $\mathrm{DN}_{3}$, no significant oscillations were revealed from the second day in DD onward under the $24.2 \mathrm{~h}$ collection regimen (Table 2). Either these cells stop oscillating, move out of phase, or cycle with periods completely different from $24.2 \mathrm{~h}$. The CRYnegative $\mathrm{LN}_{\mathrm{d}}, \mathrm{DN}_{1 \mathrm{p}}$, and $\mathrm{DN}_{2}$ cells showed significant cycling only at certain days in DD (Table 2) and changed their phase in respect to the CRYpositive neurons. The CRY-negative $\mathrm{LN}_{\mathrm{d}}$ cells cycled in phase with the CRYpositive neurons on the first day in DD, showed no visible oscillations on days $2-3$, and appeared to oscillate again on days $4-5$, but now in antiphase to the CRY-positive $\mathrm{LN}_{\mathrm{d}}$ cells (Fig. 3). ANOVA followed by a post hoc test revealed significant oscillations only at days 1 and 5 (Table 2). The CRY-negative $\mathrm{DN}_{1 \mathrm{p}}$ cells lost significant oscillations already on the first day in DD, but these came back in antiphase to the CRY-positive $\mathrm{DN}_{1 \mathrm{p}}$ cells on days 3 and 4 . On day 5, the oscillations vanished again. The CRY-negative $\mathrm{DN}_{2}$ cells showed significant cycling on days $2-4$. On these days, they cycled in antiphase to the CRYpositive neurons (Fig. 3, Table 2). The most likely explanation for this unusual behavior of the CRY-negative neurons is that they cycled with a period different from $24.2 \mathrm{~h}$ and therefore switched from in phase cycling to antiphase cycling with times 
Table 2. Significance of TIM cycling revealed by ANOVA and a post hoc test (Bonferroni's) in wild-type flies and Pdf ${ }^{01}$ mutants during 5 d in DD

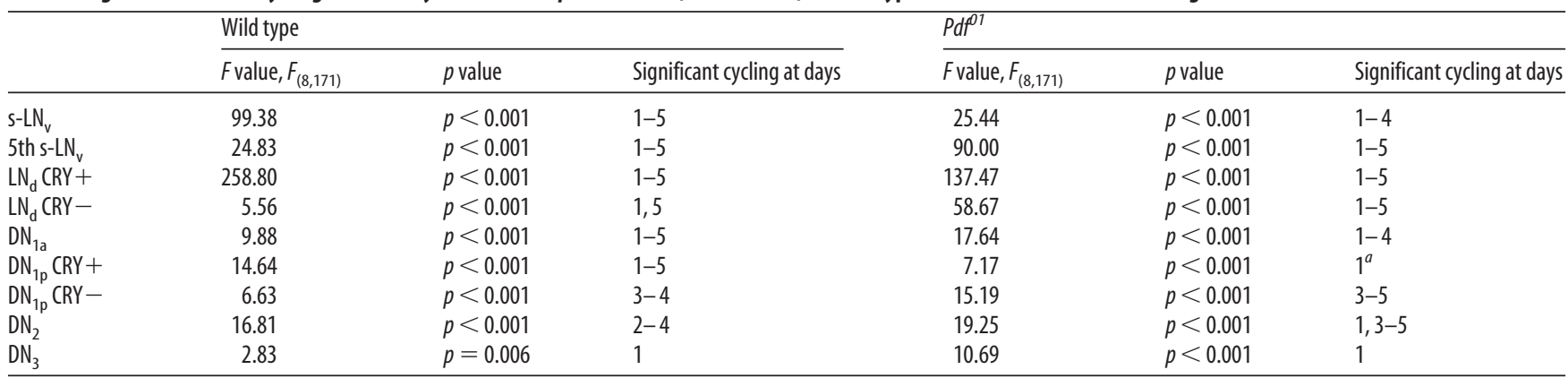

${ }^{a}$ The post hoc test found an additional significance on days $3-4$, but there is no regular circadian cycling visible (Fig. 3).

Table 3. Comparison of the effects of PDF on the clock neurons in wild-type flies and so ${ }^{\text {mda }}$ mutants

\begin{tabular}{|c|c|c|c|c|}
\hline \multirow[b]{2}{*}{ Clock neurons } & \multirow[b]{2}{*}{ Total no. } & \multirow[b]{2}{*}{$\mathrm{CRY}+1-$} & \multicolumn{2}{|l|}{ Action of PDF in } \\
\hline & & & Wild-type flies & so ${ }^{m d a}$ mutants \\
\hline $\mathrm{I}-\mathrm{LN}_{\mathrm{v}}$ & $4-5$ & $\mathrm{CRY}+$ & Not assessed & Not assessed \\
\hline$s-\mathrm{LN}_{v}$ & 4 & $\mathrm{CRY}+$ & Period lengthening (+ sustaining cycling) & Period shortening (not assessed) \\
\hline 5 th $s-\mathrm{LN}_{v}$ & 1 & $\mathrm{CRY}+$ & Period lengthening & Period lengthening \\
\hline \multirow[t]{2}{*}{$\mathrm{LN}_{\mathrm{d}}$} & 6 & $3 \mathrm{CRY}+$ & Period lengthening & Period lengthening \\
\hline & & 3 CRY- & Period shortening & Period shortening \\
\hline $\mathrm{DN}_{1 \mathrm{a}}$ & 2 & $\mathrm{CRY}+$ & Period lengthening & Period shortening \\
\hline \multirow[t]{2}{*}{$\mathrm{DN}_{1 \mathrm{p}}^{1 \mathrm{~d}}$} & $\sim 17$ & $6 \mathrm{CRY}+$ & Period lengthening (+ sustaining cycling) & Period shortening in 2 cells, period lengthening in 4 cells (not assessed) \\
\hline & & $\sim 11 \mathrm{CRY}-$ & Period shortening & Period shortening \\
\hline $\mathrm{DN}_{2}$ & 2 & CRY- & No effect & Period lengthening in 1 cell \\
\hline $\mathrm{DN}_{3}^{2}$ & $\sim 40$ & $\mathrm{CRY}-$ & No effect & Not assessed \\
\hline
\end{tabular}

of apparent arrhythmicity in between. We cannot judge the period of these CRY-negative neurons from our immunostainings, but regarding the overall short period of the perluciferase cycling in wild-type flies $(23.1 \mathrm{~h}$ ) (Fig. $2 \mathrm{D})$, it is most likely that the CRY-negative neurons cycled with short period. To be in antiphase with the CRY-positive neurons on the fifth day in DD, as was observed for the CRY-negative $\mathrm{LN}_{\mathrm{d}}$ cells, the neurons must have advanced their phase by $2.5 \mathrm{~h}$ per the $24.2 \mathrm{~h}$ day. This is equivalent to a free-running period of $21.7 \mathrm{~h}$. For the CRY-negative $\mathrm{DN}_{1 \mathrm{p}}$ and $\mathrm{DN}_{2}$, the free-running periods must be even shorter, because these were in antiphase with the CRY-positive neurons already on days 3-4 in DD. Considering these different periods $(24.2 \mathrm{~h}$ for the CRYpositive neurons and $21.7 \mathrm{~h}$ or shorter for the CRY-negative neurons), dampening oscillations of the per-luciferase with a mean period of $\sim 23 \mathrm{~h}$ are reasonable. But are these different periods and the resulting asynchrony between individual cells caused by PDF?

To answer this question, we have to look at the oscillations in $P d f^{01}$ flies. Indeed, we found that the CRY-negative $\mathrm{LN}_{\mathrm{d}}$ cells cycled with high amplitude and in phase with the CRY-positive $\mathrm{LN}_{\mathrm{d}}$ cells throughout the $5 \mathrm{~d}$ in DD (Fig. 3). This could partly explain why the per-luciferase rhythms were less dampened in $P d f^{11}$ mutants compared with wild-type flies. However, the other CRY-negative neurons of $P d f^{01}$ mutants behaved principally similar to those of wild-type flies [just differences in amplitude and the days at which significant cycling occurs are evident (Table 3)]. Furthermore, the oscillations in the CRY-positive $s-\mathrm{LN}_{\mathrm{v}}$ and $\mathrm{DN}_{1 \mathrm{a}}$ continuously lost amplitude and significant oscillations disappeared on day 5 in DD (Fig. 3, Table 2). The oscillations in the CRY-positive $\mathrm{DN}_{1 \mathrm{p}}$ vanished already on the second day in DD (Fig. 3, Table 2). Just the fifth s- $\mathrm{LN}_{\mathrm{v}}$ cell showed high-amplitude oscillations throughout the recording time. Its cycling amplitude was even higher than in wild-type flies.
The luciferase transgene is expressed in all DN groups and in the $\mathrm{LN}_{\mathrm{d}}$, but the expression strength depends on the genetic background (PDF+ or PDF-)

The fact that the CRY-positive and CRY-negative $\mathrm{LN}_{\mathrm{d}}$ cells of $P d f^{01}$ mutants remained coupled and cycled with $22.8 \mathrm{~h}$ until the end of the experiment can partly explain why the per-luciferase rhythm of $P d f^{01}$ mutants was stronger and not dampened compared with wild-type flies. However, because TIM cycling completely disappears in the six CRY-positive $\mathrm{DN}_{1 \mathrm{p}}$ cells of $P d f^{01}$ flies, whereas it persists in those of wild-type flies, it is still puzzling why $P d f^{01}$ flies showed a less dampened luciferase rhythm than wild-type flies.

Therefore, we had to make sure that indeed the same cells express the luciferase transgene in the wild-type and $P d f^{01}$ background. To do so, we recorded brains with a high-sensitivity camera (Fig. $4 A, B$ ), and we performed PER immunohistochemistry on the brains (Fig. 4C-M). For the latter, the 8-luc:9 and 8-luc:9;Pdf ${ }^{01}$ lines were crossed into the per $^{01}$ background so that only the PER-luciferase fusion protein is revealed.

The high-sensitivity camera could not reveal single cells but showed luminescent cell clusters in the dorsal and dorsolateral brain that are most likely identical with the $\mathrm{DN}$ and the $\mathrm{LN}_{\mathrm{d}}$. These cell clusters were present in wild-type (Fig. $4 A$ ) and $P d f^{11}$ (Fig. $4 B$ ) brains. The main difference between both genotypes was the luminescence intensity. The latter was higher in the $P d f^{11}$ brains, and this was especially true for the dorsolateral cluster that probably corresponds to the $\mathrm{LN}_{\mathrm{d}}$ (Fig. $4 \mathrm{~B}$ ). In addition, some $P d f^{01}$ brains showed a luminescent spot in the region of the l- $\mathrm{LN}_{\mathrm{v}}$ that was not present in the wild-type brains (Fig. 4B).

PER immunostaining gave clearer results that pointed into the same direction. In the wild-type background, all DN clusters clearly expressed the transgene, whereas staining in the $\mathrm{LN}_{\mathrm{d}}$ was notably weaker (Fig. $4 C-K$ ). We counted four to five stained $\mathrm{LN}_{\mathrm{d}}$ cells and CRY double labeling revealed that the transgene was 

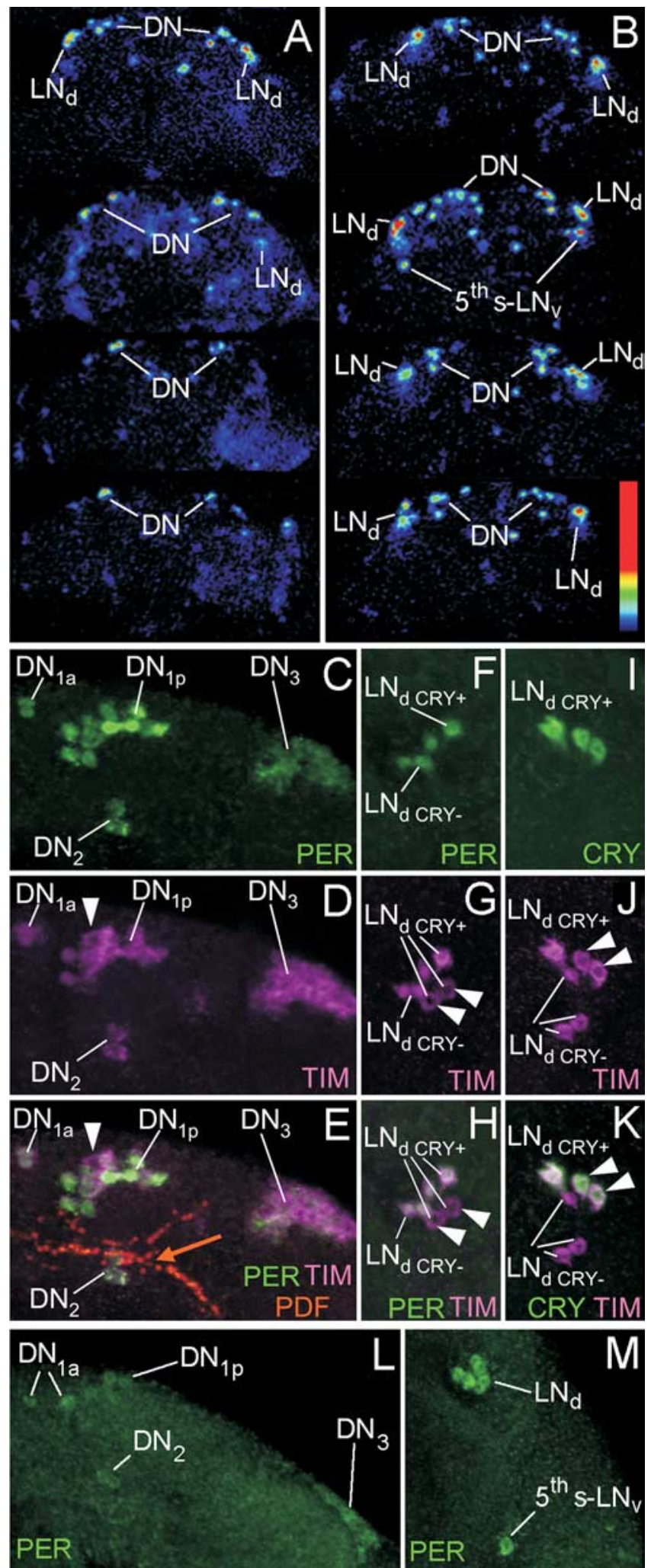

Figure 4. Spatial expression pattern of the PER-LUC (luciferase) fusion protein in brains of 8.0-Iuc:9 transgenics. $\boldsymbol{A}-\boldsymbol{B}$, Monitoring of the luciferase expression with a high-sensitive camera show luminescent spots in the dorsal and dorsolateral brain of control $(\boldsymbol{A})$ and $P d f^{01}(\boldsymbol{B})$ brains. For each genotype, four brains are shown. Note that, in the $P d f^{01}$ background, the $L N_{d}$ are stronger luminescent than the DN. $\boldsymbol{C}-\boldsymbol{K}$, To reveal transgene expression at higher resolution per $^{01} ; 8.0-$ Iuc:9 brains are triple labeled with anti-PER, anti-TIM, and anti-PDF or with anti-CRY, anti-TIM, and anti-PDF at the peak point of staining ( $1 \mathrm{~h}$ before lights-on). Overlays of all labelings are found in $\boldsymbol{E}, \boldsymbol{H}$, and $\boldsymbol{K}$. (The orange arrow in $\boldsymbol{E}$ points to the fiber tract originating from the $s-\mathrm{LN}_{v}$ and terminating in the distal dorsal protocerebrum close to the $\mathrm{DN}_{1}$ and $\mathrm{DN}_{2}$ ). always expressed in the three CRY-negative $\mathrm{LN}_{\mathrm{d}}$ cells and additionally in one to two CRY-positive cells (Fig. $4 H, K$ ). In rare cases ( $\sim 10 \%$ of the brains), we found the transgene additionally in the CRY-positive fifth s-LN $\mathrm{LN}_{\mathrm{v}}$ (data not shown). In the $P d f^{01}$ background, all six $\mathrm{LN}_{\mathrm{d}}$ cells plus the fifth s- $\mathrm{LN}_{\mathrm{v}}$ expressed the transgene, and the staining intensity was much higher than in the wild-type background (Fig. $4 M$ ). In contrast, the staining intensity appeared considerable weaker in the DN clusters (Fig. $4 L$ ).

Our results indicate that the transgene expression level was influenced by the genetic background. This could fully explain the different per-luciferase oscillations we got for wild-type and $P d f^{01}$ flies (Fig. $2 C$ ). In wild-type flies, mainly the DN clusters and the CRY-negative $\mathrm{LN}_{\mathrm{d}}$ cells contribute to the luciferase cycling. Because the CRY-negative $\mathrm{LN}_{\mathrm{d}}$ and DN cells most probably cycle with shorter period than the CRY-positive DN cells, it is understandable that the overall oscillation is dampening. In $P d f^{01} \mathrm{mu}-$ tants, the situation is different. Here, mainly the $\mathrm{LN}_{\mathrm{d}}$ cluster and the fifth $\mathrm{s}-\mathrm{LN}_{\mathrm{v}}$ seem to contribute to the per-luciferase cycling. These cells continue to cycle in synchrony with $22.8 \mathrm{~h}$ period under DD conditions (Fig. 3), and this may explain the highamplitude not-dampened oscillation of the per-luciferase (Fig. $2 C, E)$.

In summary, we can say that PDF affects the clock neurons in a complex manner: (1) PDF mediates synchrony within certain groups of clock neurons as the $s-\mathrm{LN}_{\mathrm{v}}$, and the $\mathrm{DN}_{1 \mathrm{a}}$. Simultaneously, PDF seems to lengthen the period of these neurons from 22.8 to $24.2 \mathrm{~h}$. (2) PDF similarly lengthens the periods of some clock neurons as the CRY-positive $\mathrm{LN}_{\mathrm{d}}$ and the fifth $\mathrm{s}-\mathrm{LN}_{\mathrm{v}}$; but within these groups, PDF is not necessary for synchronous highamplitude cycling. (3) PDF shortens the periods of other clock neurons as the CRY-negative $\mathrm{LN}_{\mathrm{d}}$; again PDF is not necessary for synchronous high-amplitude cycling in this group. (4) PDF appears necessary for rhythmicity in the CRY-positive $\mathrm{DN}_{1 \mathrm{p}}$, because cycling in this group stops immediately after transfer into DD. (5) PDF has no obvious effect on the CRY-negative $\mathrm{DN}_{1 p}, \mathrm{DN}_{2}$, and $\mathrm{DN}_{3}$ cells, because these behaved similarly in wild-type flies and $P d f^{\ominus 1}$ mutants.

\section{Enhanced PDF levels in the dorsal brain lead to period}

shortening in the CRY-positive $\mathrm{DN}_{1 \mathrm{a}}$, in two $\mathrm{DN}_{1 \mathrm{p}}$, and in the four PDF-positive $s-\mathrm{LN}_{\mathrm{v}}$ cells

Despite the period-shortening effect of PDF on the CRY-negative $\mathrm{LN}_{\mathrm{d}}$ cells, no short period component is visible in the freerunning rhythm of wild-type flies. Obviously, these neurons do not visibly contribute to the behavioral rhythm under DD conditions in wild-type flies. The same seems to apply to $s o^{1}$ mutants that have elevated PDF levels in the aMe and show behavioral rhythms with $24.6 \mathrm{~h}$ periods (Fig. 5A) (Wülbeck et al., 2008). Again, only the period-lengthening effects of PDF are visible in the behavior. This is obviously different when PDF is elevated to very high levels in the dorsal brain as true in $s o^{m d a}$ mutants (Wülbeck et al., 2008). Under these circumstances, a PDF-dependent short period $(21.3 \mathrm{~h})$ component appeared in the activity rhythm

PER labeling is only present in neurons that express the transgene $(\boldsymbol{C}, \boldsymbol{F})$, whereas endogenous TIM is found in all clock neurons $(\boldsymbol{D}, \boldsymbol{G}, \boldsymbol{J})$. However, nuclear TIM occurs only in the PER-positive cells (arrowheads point to cells that had cytoplasmic TIM and consequently were PER-negative). $\boldsymbol{C}, \boldsymbol{F}$, PER labeling shows that the 8.0-luc:9 transgene is expressed in the $\mathrm{DN}_{1 \mathrm{a}}$, most $\mathrm{DN}_{1 \mathrm{p}}$, the $\mathrm{DN}_{2}$, most $\mathrm{DN}_{3}$, and in four $\mathrm{LN}_{\mathrm{d}}$ cells. $\boldsymbol{E}, \boldsymbol{H}, \boldsymbol{K}, \mathrm{CRY}$ and TIM labeling show that three of the four PER-positive $L N_{d}$ cells are CRY-negative (the arrowheads in $\boldsymbol{D}-\boldsymbol{K}$ point to the CRY-negative cells that have cytoplasmic TIM). $L, M$, Transgene expression in the $P d f^{01}$ background. Note that the DN cells $(\boldsymbol{L})$ are much weaker labeled as in the wild-type background, but that all six $\mathrm{LN}_{\mathrm{d}}$ are strongly labeled $(\boldsymbol{M})$. Additionally, PER is always present in the fifth $s-\mathrm{LN}_{v}$ cell $(\boldsymbol{M})$. 

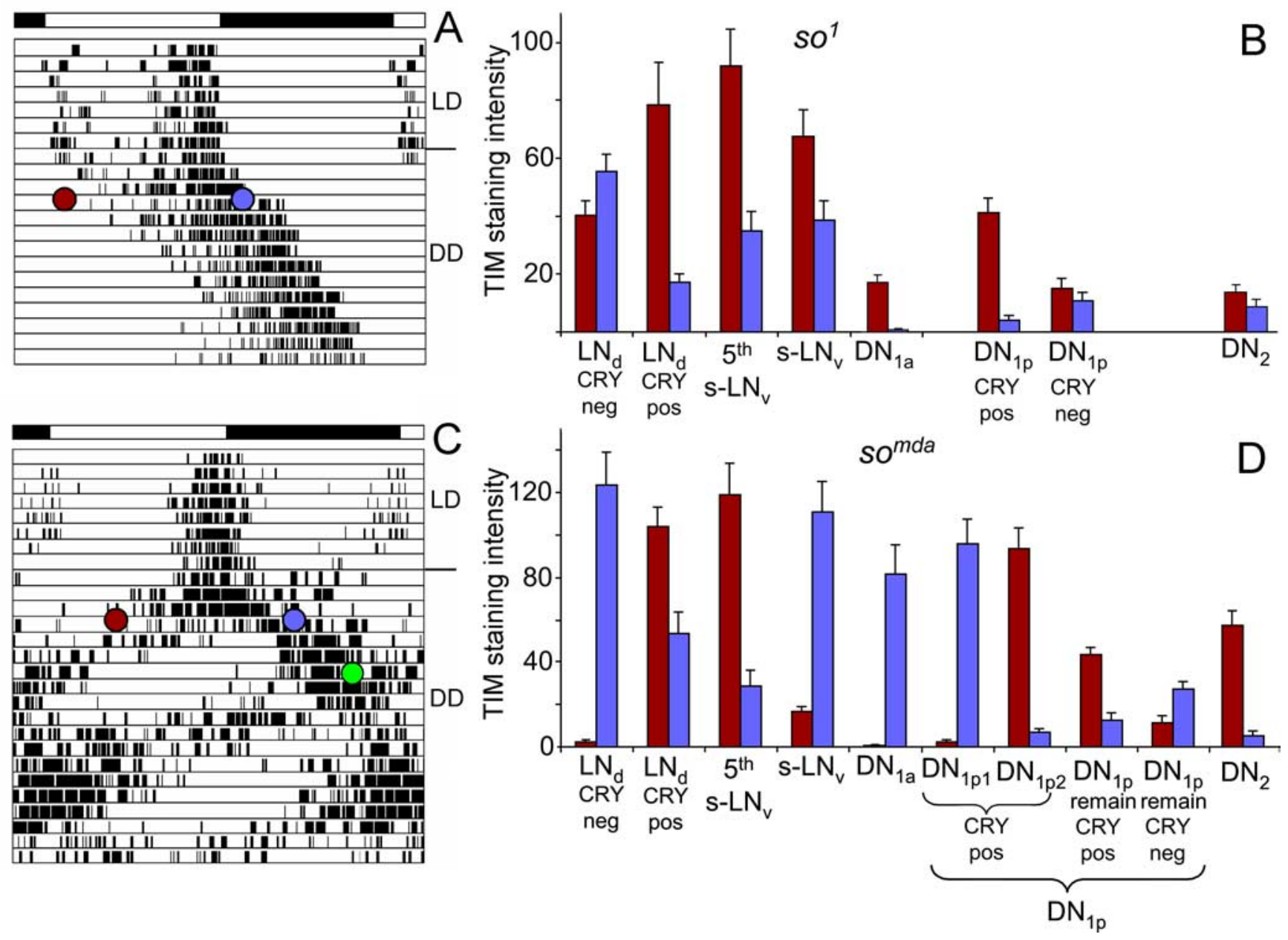

Figure 5. Actograms of $s 0^{1}$ and $s 0^{m d a}$ mutants and TIM staining in the clock neurons of both mutants at two times on days 3-4 in DD (red and blue points). Ten flies were stained at each time for each mutant, respectively. As can be seen in the example actograms, $s 0^{1}$ mutants show one rhythm free-running with long period as soon as released to $D D(A)$, whereas so ${ }^{m d a}$ mutants reveal two rhythmic components in DD, which free-run with short and long periods, respectively, and that were $180^{\circ}$ out of phase at the times of staining (C). $\boldsymbol{B}$, In $50^{1}$ mutants, the CRY-positive clock neurons were strongly TIM-immunoreactive in the early subjective morning, just before the flies became active ( $\boldsymbol{A}$, red point; $\boldsymbol{B}$, red columns) and less stained in the subjective evening, when the flies were most active ( $\boldsymbol{A}$, blue point; $\boldsymbol{B}$, blue columns). The CRY-negative neurons did not show this difference. ANOVA revealed a significant influence of the time of staining on labeling intensity $\left(F_{(1,165)}=30.68 ; p<0.001\right)$ and that this influence was dissimilar in the different neuronal groups $\left(F_{(7,165)}=3.96 ; p<0.001\right)$. The posthoc test showed that only the CRY-positive neurons showed significantly higher TIM staining in the early subjective morning compared with the evening. No significant differences were revealed for the CRY-negative neurons. $D$, In so ${ }^{m d a}$ mutants, ANOVA showed again a significant influence of time on staining intensity $\left(F_{(1,179)}=4.62 ; p=0.03\right)$, which was strongly dissimilar in the different neurons $\left(F_{(8,179)}=34.78 ; p<0.001\right)$. No significant staining differences were only found in the $C R Y$-negative $\mathrm{DN}_{1 \mathrm{p} \text { remain. }}$. The other neurons were either strongly TIM-immunoreactive at the activity maximum of the long-period component ( $C$, blue point; $\boldsymbol{D}$, blue columns) or at the activity maximum of the short-period component ( $\boldsymbol{C}$, red point; $\boldsymbol{D}$, red columns). For additional explanations, see text. The green point in $\boldsymbol{C}$ indicates the time at which short- and long-period components crossed each other and were consequently in phase again. At this day, the different clock neurons cycled in synchrony with each other (supplemental Fig. S1, available at www.jneurosci.org as supplemental material). Error bars indicate SEM.

(Fig. 5C). Most interestingly, this short period is similar to the short period we calculated for the CRY-negative neurons in wildtype flies. We wondered why in $s o^{\text {mda }}$ mutants this short period appeared in the behavioral rhythm. A possible explanation would be that, in $s 0^{m d a}$ mutants, more clock neurons were accelerated by $\mathrm{PDF}$ and consequently contributed to the activity rhythm. We therefore asked whether there are subsets of pacemakers that are accelerated by increased PDF levels in the brain.

To find out which neurons run with short and which with long period in $s 0^{\text {mda }}$ mutants, we applied a method that has been previously proven to work successfully for internally desynchronized rhythms (de la Iglesia et al., 2004; Rieger et al., 2006). We immunostained so ${ }^{m d a}$ brains at two time points in DD at which the two activity components that free-ran with short and long periods in $s 0^{m d a}$ mutants were $180^{\circ}$ out of phase (Fig. $5 \mathrm{C}$ ). Fortunately, so ${ }^{m d a}$ individual flies show all a rather stereotyped activ- ity pattern desynchronizing into two components with short and long periods, respectively. The two activity components became completely out of phase with each other on days 3-4 in DD, crossed each other, and remained together for a short while on days $6-8$, and then separated again and were once more out of phase on days 10-11. The intersection of the two components continued until the end of the experiment (Fig. 5C).

$s o^{1}$ mutants that showed just a long period, but no internal desynchronization in the activity patterns served as controls. For these, we chose the times of highest and lowest activity on days $3-4$, respectively (Fig. 5A). We expected from data of previous studies (Yoshii et al., 2004; Rieger et al., 2006) that high TIM immunoreactivity is present in the early subjective morning (slightly before the morning peak of activity) (Fig. 5A, red point) and low TIM immunoreactivity is present in the subjective evening (during the evening activity peak) (Fig. $5 \mathrm{~A}$, blue point) in 
timepoint
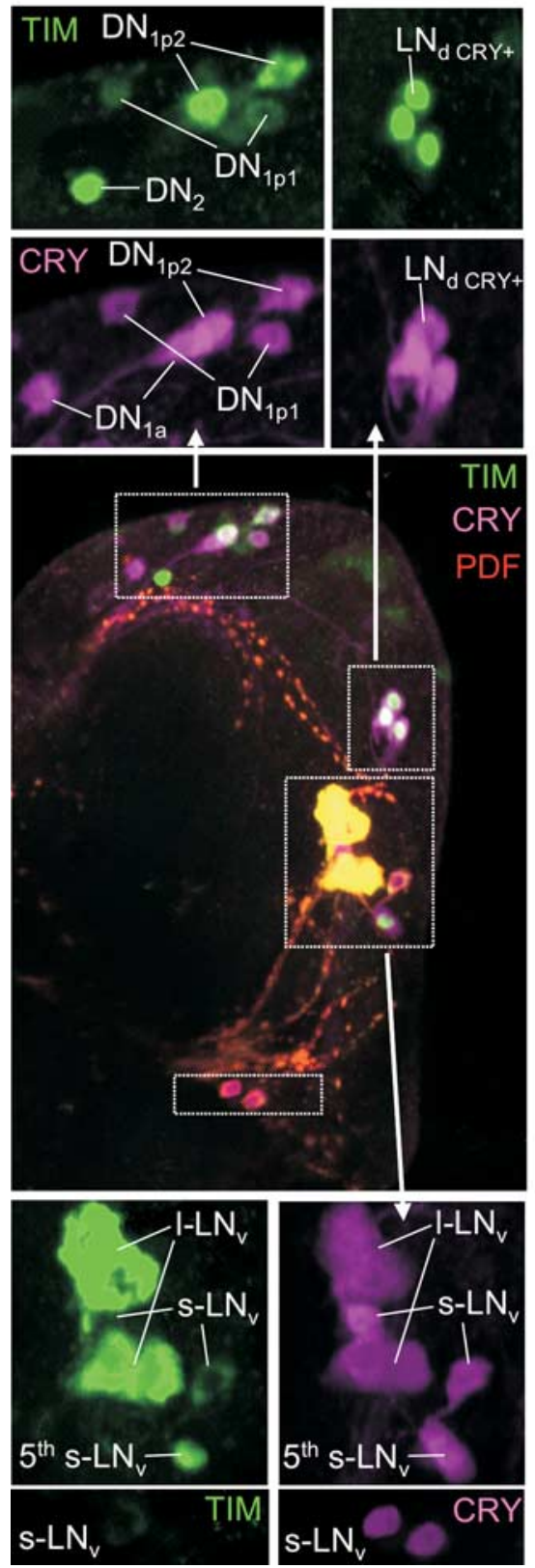

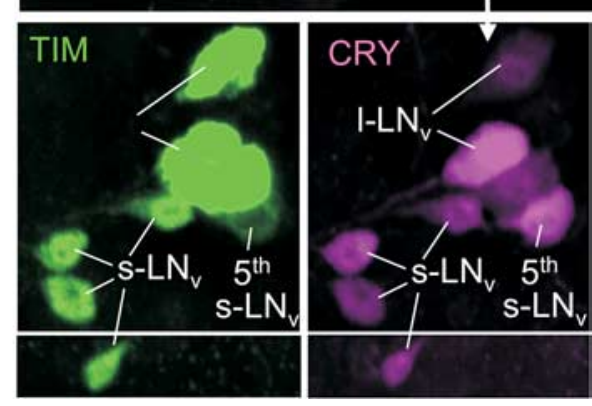

timepoint
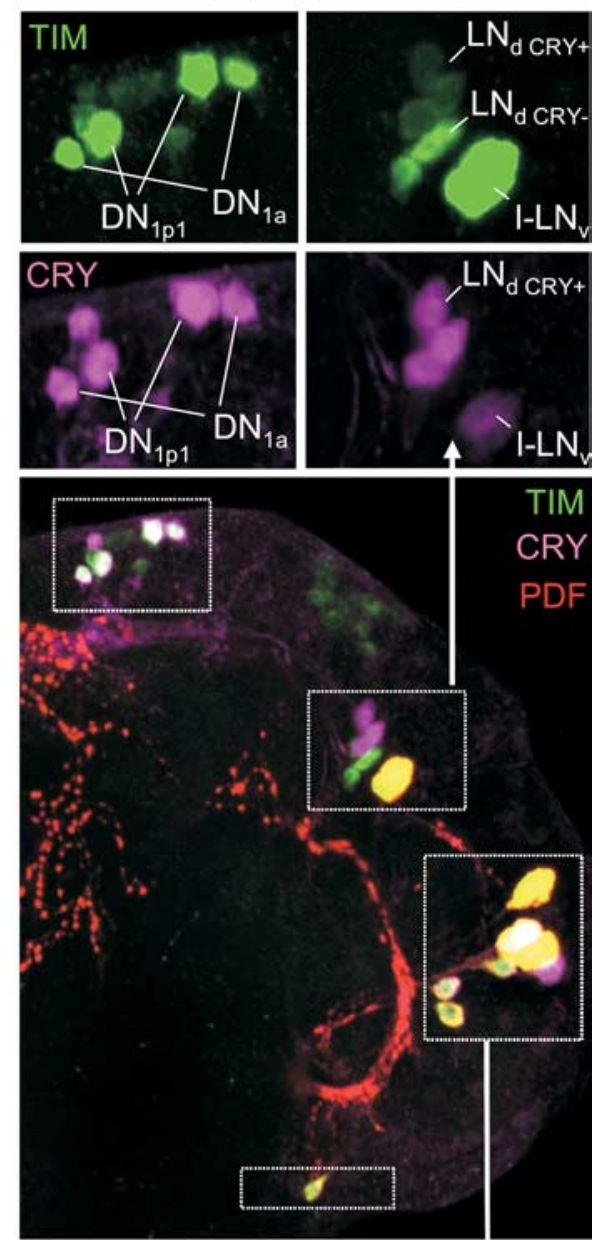

Figure 6. TIM labeling showing the internal desynchronization among the dorsal and lateral neurons in so ${ }^{m d a}$ mutants stained at the two time points marked by red and blue in Figure 5 (red time point, left panel; blue time point, right panel). Both brains were triple stained with anti-TIM (green), anti-CRY (magenta), and anti-PDF precursor (orange). The large pictures in the center of both panels depict the overlay of all three labelings (combination of 10 confocal stacks). Depending on their amount of TIM and CRY, the PDF-positive $L_{v}$ cells appear in yellow to orange, neurons that have no PDF (e.g., some $L_{d}$ and $D_{1}$ ) but equal amounts of TIM and CRY appear in white, those that contain only TIM are in green, and those that contain CRY but no or only tiny amounts of TIM are in magenta. To reveal TIM and CRY staining more clearly, single labeling of TIM and CRY of several clock neurons were enlarged and shown separately above and below the central pictures ( $\mathrm{DN}_{1-2}$ and $\mathrm{LN}_{\mathrm{d}}$ on top, $\mathrm{LN}_{v}$ on bottom; see insets in the large pictures). At the "red" time point (left panels), TIM was high in one pair of CRY-positive $\mathrm{DN}_{1 \mathrm{p}}$ (the DN $\mathrm{DN}_{1 \mathrm{p}}$ ) (Fig. 6) and in one cell of the $\mathrm{DN}_{2}$ (note that the $\mathrm{DN}_{2}$ cells are (RY-negative). No TIM labeling was found in the CRY-positive $\mathrm{DN}_{1 \mathrm{a}}$, and only weak TIM labeling in the CRY-positive $\mathrm{DN}_{1 \mathrm{p} 1}$ and some CRY-negative DN $\mathrm{DN}_{1 \mathrm{p}}$. Among the $\mathrm{LN}_{\mathrm{d}}$, TIM was high in the three CRY-positive $\mathrm{LN}_{d}$, and no TIMstaining at all was present in the three CRY-negative $L_{d}$. Among the $L N_{v}$, TIM was high in the fifth s- $L_{v}$ and in the I- $L_{v}$ that were not evaluated. Almost no TIM was found in the PDF-positives-LN . At the "blue" time point (right panels), TIM was high in the $\mathrm{DN}_{1 \mathrm{a}}$

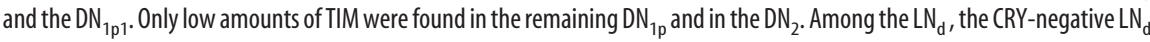
were strongly stained by TIM, whereas the CRY-positive $L_{d}$ contained only little TIM. Of the $L_{v}$, again the I-LN $N_{v}$ were strongly stained (not evaluated), but now the PDF-positive s- $\mathrm{LN}_{v}$ were highly TIM-immunoreactive and little TIM was present in the fifth s- $\mathrm{LN}_{\mathrm{v}}$. all the cells that contribute to the activity (the CRY-positive neurons). This was indeed the case (Fig. 5B). ANOVA revealed significant differences in staining intensity between both time points for all CRYpositive neurons. Additionally, we found TIM to be mainly nuclear at the times of strong staining, whereas TIM was mainly cytoplasmic at the time of low staining.

We did not see any significant differences in staining intensity between the two time points in the CRY-negative neurons. This is in agreement with our present results for wild-type flies, because these cells seem to free-run with short period and might neither be in phase nor in complete antiphase to the CRY-positive neurons on days 3-4 in DD (note that the CRYpositive neurons of $s o^{1}$ mutants cycle with a period of $24.6 \mathrm{~h}$ and not with a $24.2 \mathrm{~h}$ period; therefore, we could not deduce the days with in phase and antiphase cycling between CRY-positive and CRY-negative neurons from the wild type shown in Fig. 3).

For $s o^{m d a}$, we chose the times of high activity of the short component and that of high activity of the long component on days 3-4 in DD, respectively (Fig. 5C). According to our previous results (Rieger et al., 2006), we expected the neurons that control the short component to be stained the strongest at the activity maximum of the long component (Fig. 5C, blue point) and those that control the long component to be stained the strongest at the activity maximum of the short component (Fig. $5 C$, red point).

As found for $s o^{1}$ mutants and wild-type flies, the majority of CRY-negative neurons appeared to cycle with short period in $s o^{\text {mda }}$ mutants (most evident for the CRYnegative $\mathrm{LN}_{\mathrm{d}}$ cells), whereas mainly CRYpositive neurons (the three $\mathrm{LN}_{\mathrm{d}}$ cells, the fifth $s-\mathrm{LN}_{\mathrm{v}}$, and two CRY-positive $\mathrm{DN}_{1 \mathrm{p}}$ cells) ran with long period (Fig. 5D). However, most interestingly, several CRYpositive neurons did now join the CRYnegative neurons and did also cycle with short period. These were the four $s-\mathrm{LN}_{\mathrm{v}}$ cells, the two $\mathrm{DN}_{1 \mathrm{a}}$ cells, and two cells of the $\mathrm{DN}_{1 \mathrm{p}}$ that were strongly CRY-positive (Fig. 5D). However, one $\mathrm{DN}_{2}$ cell appeared to cycle with long period (Figs. 5D, 6).

The asynchrony within the different groups of clock neurons can be nicely seen in Figure 6. This was especially evident for the $\mathrm{LN}_{\mathrm{d}}$ cluster: At the time marked with the red point, the three CRY-positive $\mathrm{LN}_{\mathrm{d}}$ cells were strongly immunoreactive against TIM and the three CRY-negative $\mathrm{LN}_{\mathrm{d}}$ cells were not stained at all, whereas at the blue marked time point, the three 
CRY-negative $\mathrm{LN}_{\mathrm{d}}$ cells were strongly TIM-positive and the three CRY-positive cells were only weakly stained. The same asynchrony occurred between the PDF-positive s- $\mathrm{LN}_{\mathrm{v}}$ cells and the PDF-negative fifth s- $\mathrm{LN}_{\mathrm{v}}$ (Fig. 6): At the time marked with the red point, the fifth s-LN $\mathrm{L}_{\mathrm{v}}$ was strongly immunoreactive against TIM and the PDF-positive s- $\mathrm{LN}_{\mathrm{v}}$ cells were not, whereas at the blue marked time point, the PDF-positive s- $\mathrm{LN}_{\mathrm{v}}$ cells were strongly TIM-positive and the fifth s- $\mathrm{LN}_{\mathrm{v}}$ was not stained.

To make sure that the internal desynchronization of the molecular oscillations we found on days 3-4 in DD is not a permanent state in $s 0^{m d a}$ mutants, we also stained few flies on day 6 in DD. On day 6 , the long and short period component crossed each other, and as a consequence both were in phase for a short time interval (Fig. 5C, green point). Accordingly, no asynchrony among the CRY-positive and CRY-negative $\mathrm{LN}_{\mathrm{d}}$ cells should be visible. This was indeed the case. We found prominent TIM staining in all $\mathrm{LN}_{\mathrm{d}}$ cells during the activity trough and weaker staining during the activity peak (supplemental Fig. S1, available at www.jneurosci.org as supplemental material). Similarly, the PDF-positive s- $\mathrm{LN}_{\mathrm{v}}$ cells and the PDF-negative fifth $s-\mathrm{LN}_{\mathrm{v}}$ cell seemed to be in phase with each other. As was expected, both were more prominently stained during the activity trough and weaker stained during the activity peak (supplemental Fig. S1, available at www.jneurosci.org as supplemental material).

In summary, we found that high PDF levels in the dorsal brain correlated with a permanently shortened period of the CRYnegative $\mathrm{LN}_{\mathrm{d}}$ and $\mathrm{DN}_{\mathrm{lp}}$ cells plus that of the CRY-positive $\mathrm{DN}_{\mathrm{la}}$, two CRY-positive $\mathrm{DN}_{1 \mathrm{p}}$, and the PDF-positive s- $\mathrm{LN}_{\mathrm{v}}$ cells. The short-period rhythm of the s- $\mathrm{LN}_{\mathrm{v}}$ is probably the reason why the short-period component was visible in the activity pattern of $s o^{m d a}$ mutants. However, PDF appeared to lengthen the period of the PDF-negative fifth-sLN ${ }_{v}$, the CRY-positive $\mathrm{LN}_{\mathrm{d}}$ cells, and one $\mathrm{DN}_{2}$ cell, and these may control the long-period component in the activity rhythm. Figure 7 shows the neurons that seemed to shorten their period on PDF in red and those that seemed to lengthen their period in blue for so $o^{m d a}$ mutants. Table 3 compares the effects of PDF on the different neurons in wild-type and $s o^{m d a}$ flies.

\section{PDF is necessary for adaptation of the activity rhythm to different photoperiods}

Most interestingly, the same scenario that the PDF-positive s- $\mathrm{LN}_{\mathrm{v}}$ and the fifth PDF-negative s- $\mathrm{LN}_{\mathrm{v}}$ (together with one-half of the $\mathrm{LN}_{\mathrm{d}}$ cells) showed short and long periods respectively was observed previously for wild-type flies and $c r y^{b}$ mutants under constant-light conditions (Rieger et al., 2006; Helfrich-Förster et al., 2007b). In this case, light was the factor that speeded up and slowed down the relevant neurons.

Light is the most important Zeitgeber for synchronizing circadian clocks to the $24 \mathrm{~h}$ day. Prolonged light exposure in the summer makes the morning activity of flies to advance (speed up) to the beginning of the day and the evening activity to delay (slow down) to the end of the day to avoid the midday heat (Majercak et al., 1999; Rieger et al., 2003, 2006). This adaptation is known for many animals including humans, and it is important for survival (Foster and Roenneberg, 2008). Pittendrigh and Daan (1976) proposed a model in which this adaptation to long summer days is achieved by two circadian oscillators that respond differently to light. Drosophila was the first animal in which the anatomical substrates of the two oscillators could be traced to certain clock neurons (Grima et al., 2004; Stoleru et al., 2004, 2005, 2007), and in which it was shown that certain clock

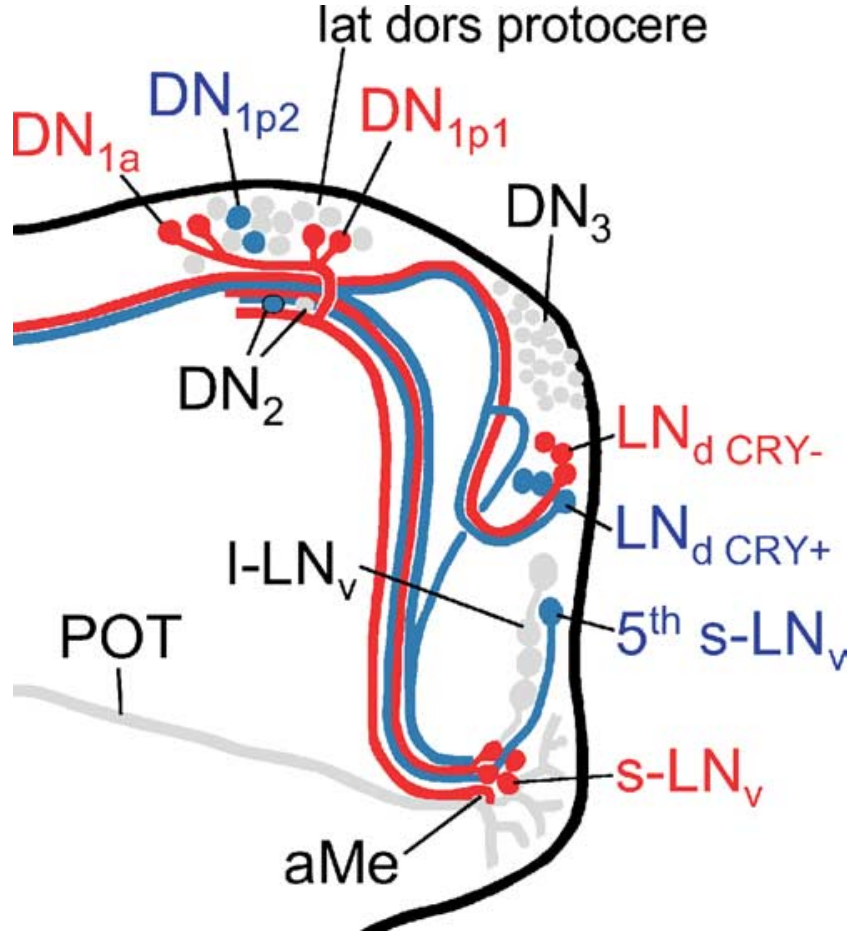

Figure 7. Diagram summarizing our present view on the differential action of PDF on the clock neurons in so ${ }^{m d a}$ mutants (only the right brain hemisphere is shown). Neurons that lengthen their period on excessive amounts of PDF in the dorsal brain are shown in blue. Neurons that shorten their period under the same conditions are shown in red. Neurons not assessed in the present study or neurons with unclear response to PDF are shown in gray. Note that the aberrant arborizations of the I- $L N_{v}$ are omitted for better clarity. The $-L_{v}$, fifth s- $L N_{v}$, I- $\mathrm{LN}_{\mathrm{v}}, \mathrm{DN}_{1 \mathrm{a}}$, and the three CRY-positive $\mathrm{LN}_{\mathrm{d}}$ neurons arborize in the aMe, in which PDF secreted by the I-LN $\mathrm{L}_{\mathrm{v}}$ cells might serve as coupling factor in wild-type flies (Wülbeck et al., 2008, their Discussion). Furthermore, fibers from the $s-\mathrm{LN}_{v}$, the $\mathrm{DN}_{1 \mathrm{a}}, \mathrm{DN}_{1 \mathrm{p} 1}$, and the CRY-positive and -negative $\mathrm{LN}_{\mathrm{d}}$ cells may contact each other in the lateral dorsal protocerebrum (lat dors protocere), in which PDF seems to be rhythmically released from the s-LN $\mathrm{LN}_{\mathrm{v}}$ cells (Park et al., 2000). The fifth $\mathrm{s}-\mathrm{LN}_{\mathrm{v}}$ cell was also found to project toward the dorsolateral protocerebrum, but it is not clear whether it reached this area or whether it terminated before (Helfrich-Förster et al., 2007). The I-LN $\mathrm{N}_{v}$ cells do not project into the dorsolateral brain in wild-type flies, but do so extensively in so ${ }^{\text {mda }}$ mutants (Wülbeck et al., 2008). We suppose that extensive amounts of PDF secreted into this brain region shorten the periods of the CRY-positive $\mathrm{DN}_{1 \mathrm{a}}$ and $\mathrm{DN}_{1 \mathrm{p} 1}$ cells. The latter two groups may feedback on the $s-\mathrm{LN}_{v}$ forcing them also to free-run with short period (for details, see supplemental Discussion, available at www.jneurosci.org as supplemental material).

neurons indeed speeded up or slowed down in response to light (Rieger et al., 2006).

According to our present results, PDF may also be crucially involved in the speed control of the clock neurons, and thus also in the adaptation of the activity patterns to long days. If true, $P d f^{01}$ mutants should not be able to adapt to long days in the normal manner. To test this, we subjected wild-type flies and $P d f^{01} \mathrm{mu}-$ tants to different photoperiods.

We found that wild-type flies phase-advanced their morning activity and phase-delayed their evening activity with increasing photoperiod as reported previously (Fig. 8A-E) (Rieger et al., 2003). However, $P d f^{\rho 1}$ mutants were not able to behave in this manner (Fig. $8 \mathrm{~F}-J$ ). As reported previously, they showed little activity in the morning (Renn et al., 1999). Therefore, we did concentrate our analysis on the evening activity. The latter was very pronounced in $P d f^{01}$ mutants and occurred earlier in the day than in wild-type flies fitting to their short period under DD conditions (Renn et al., 1999). However, in clear contrast to wildtype flies, the evening activity did not show any phase adaptations 


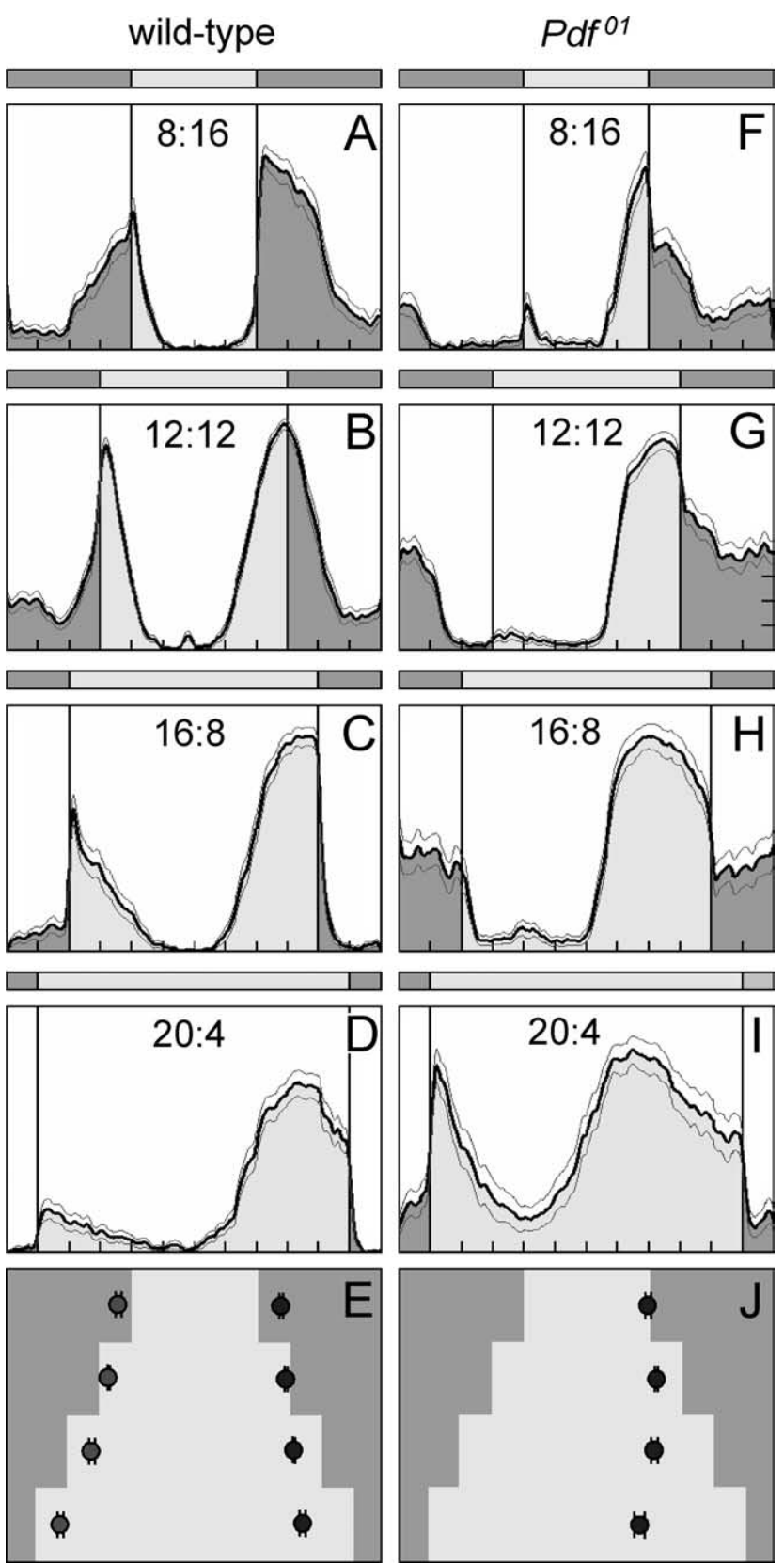

Figure 8. Average activity profiles of wild-type flies and $P d P^{17}$ mutants under different photoperiods. Photoperiods are indicated in the diagrams, whereby 8:16 means $8 \mathrm{~h}$ day and $16 \mathrm{~h}$ night; $12: 12$, $12 \mathrm{~h}$ day and $12 \mathrm{~h}$ night; $16: 8,16 \mathrm{~h}$ day and $8 \mathrm{~h}$ night; and 20:4, $20 \mathrm{~h}$ day and $4 \mathrm{~h}$ night. Each activity profile represents the average of 30 flies. Wild-type flies showed prominent morning and evening activity peaks under all photoperiods. The morning peaks advanced with increasing day length, whereas the evening peaks delayed. As a consequence, the midday trough became larger the longer the day length. This can nicely be seen in the phase plot of morning and evening peaks ( \pm SEM) $(\boldsymbol{E})$. $P d P^{01}$ mutants did not show a clear morning peak. Under LD 8:16 (F) and 20:4 (I), the flies seem to respond to lights-on with an increase of activity, and in LD 16:8 $(\boldsymbol{H})$, a small peak was present $\sim 4 \mathrm{~h}$ after lights-on; furthermore, an activity bout was present in the middle of the night under all photoperiods except 20:4 (I). None of these peaks could be unequivocally regarded as morning peak, and therefore no average phases of the morning peak was calculated $(J)$. The evening peak was well pronounced in $P d P^{01}$ mutants. It occurred earlier than in wild-type flies, and it did not delay with increasing day length $(J)$. According to these results, $P d P^{p 1}$ mutants are unable to avoid the midday heat in long summer days.

in respect to the photoperiod (Fig. $8 F-J$ ). Instead of delaying with increasing day length, the maximum of the evening peak did even slightly advance. We conclude that PDF is necessary for the flies to adapt normally to different photoperiods. Thus, the major role of PDF under natural conditions might be to adjust the phasing of the different players in the clock and perhaps mediate the effects of light on the clock neurons under long days. Future studies have to reveal the oscillations of the clock neurons in $P d f^{01}$ mutants under long and short days.

\section{Discussion}

Our data underline previous findings that PDF has multiple roles in the fruit fly clock. First, PDF is necessary for the maintenance of robust rhythms within certain groups of clock neurons; simultaneously, PDF lengthens the period of most of these clock cells. Second, in other groups of clock neurons, PDF has no influence on the maintenance of rhythmicity, but it clearly influences clock speed; either PDF lengthens or it shortens period.

The first effect of PDF is in agreement with the hypothesis that PDF lengthens the periods of the clock neurons and simultaneously couples their oscillations so that a coherent rhythm is produced (Peng et al., 2003). This hypothesis is supported by the observations that $P d f^{01}$ and PDF receptor mutants are arrhythmic or show weak short-period behavioral rhythms (Renn et al., 1999; Hyun et al., 2005) fitting to an asynchronous cycling of several clock neurons and short-period rhythms in other neurons in absence of PDF (Klarsfeld et al., 2004; Lin et al., 2004; Wu et al., 2008). Furthermore, PDF fulfils the prerequisites of a synchronizing clock factor: PDF is expressed in $\sim 10 \%$ of the clock neurons that are highly connected to the other clock cells (Fig. 7), PDF seems to be released rhythmically (Park et al., 2000), and its receptor is expressed by most clock neurons (Shafer et al., 2008).

Synchronizing and period-lengthening effects of PDF on the clock have also been reported for the cockroach (Schneider and Stengl, 2005). Here, PDF injections into the pacemaker center phase-delayed the activity rhythm (Petri and Stengl, 1997). Permanent phase delays are equivalent to a period lengthening, and Petri and Stengl (2001) showed that phase delays can couple the oscillators. Thus, the decelerating and coupling effects of PDF on the clock may be more generally valid.

Furthermore, the just-described effects of PDF strongly resemble those described for VIP in the circadian clock of mammals, the suprachiasmatic nucleus (SCN) (Aton and Herzog, 2005). VIP is expressed in $15 \%$ and the VIP receptor is expressed in $60 \%$ of the SCN neurons (Abrahamson and Moore, 2001); VIP is rhythmically released from the rat SCN in vitro (Shinohara et al., 1995) and shifts both behavioral and SCN firing rhythms (Piggins et al., 1995; Reed et al., 2001). VIP has two distinct roles in the SCN: maintaining circadian rhythmicity in a subset of clock neurons and maintaining synchrony between intrinsically rhythmic neurons (Aton et al., 2005). Approximately $50 \%$ of the rhythmically firing neurons in the SCN require VIP to do so; the other one-half do not depend on VIP concerning rhythmic firing, but VIP is necessary to synchronize their firing rhythms.

In Drosophila, we cannot easily distinguish between clock neurons that need PDF to be rhythmic and clock neurons that remain rhythmic without PDF, but lose internal synchrony, because we could not record individual neurons. Nevertheless, it is very likely that these two populations do also exist in the fly. The CRY-positive $\mathrm{DN}_{1 \mathrm{p}}$ may belong to the first population, because their cycling is lost immediately after transfer into DD (Fig. 3). However, the oscillations in the s- $\mathrm{LN}_{\mathrm{v}}$ and the CRY-positive $\mathrm{DN}_{1 \mathrm{a}}$ dampen slowly, indicating that here PDF is needed for mutually synchronizing individual oscillations within the group. Without PDF, these became slowly asynchronous. 
Nevertheless, in Drosophila, a third group of neurons seems to exist that are independent of PDF concerning rhythmicity and internal synchronization, but that are strongly influenced by PDF regarding their period. These are the $\mathrm{LN}_{\mathrm{d}}$ and the fifth $s-\mathrm{LN}_{\mathrm{v}}$. Most interestingly, PDF lengthened the period of the fifth $s-\mathrm{LN}_{\mathrm{v}}$ and the CRY-positive $\mathrm{LN}_{\mathrm{d}}$, whereas it shortened that of the CRY-negative $\mathrm{LN}_{\mathrm{d}}$. The period-shortening effect of PDF is completely unexpected, especially because we never observed a short-period component in the activity rhythm of wild-type flies. We have to conclude that the CRY-negative $\mathrm{LN}_{\mathrm{d}}$ (and other CRY-negative neurons as the $\mathrm{DN}_{1 \mathrm{p}}$ that run with short period) do not obviously contribute to the locomotor rhythms in DD.

Our hypothesis that PDF shortens the period of some clock neurons and lengthened that of others is strongly supported by the appearance of short- and long-period components in the activity rhythm of $s o^{m d a}$ mutants. so ${ }^{m d a}$ mutants have elevated PDF levels in the dorsal brain and in the aMe that are caused by misrouted l- $\mathrm{LN}_{\mathrm{v}}$ fibers (Wülbeck et al., 2008). Most interestingly, a correlation analysis with neural mutants showing variable numbers of PDF fibers in the dorsal brain and the aMe showed that the period of the short component became shorter the more PDF fibers were present in the dorsal brain, and that of the long period became longer with increasing number of PDF fibers in the aMe, suggesting that PDF has different effects in different brain areas (Wülbeck et al., 2008). Here, we identified the neuronal groups that shortened and lengthened periods in response to PDF, respectively (Fig. 7, Table 3).

But how can we explain that the same peptide influences the periods differently in various clock neurons? Shafer et al. (2008) found that all clock neurons (except the $1-\mathrm{LN}_{\mathrm{v}}$ that do not seem to express the PDF receptor) respond to PDF with an increase in cAMP levels. Certainly, increased cAMP levels do not necessarily lead to the same cellular responses. The clock cells may express different sets of kinases and phosphatases that may change the phosphorylation of the clock proteins in opposite manners. But how can we explain that certain neurons like the $\mathrm{DN}_{1 \mathrm{a}}, \mathrm{DN}_{1 \mathrm{pl}}$, and the s- $\mathrm{LN}_{\mathrm{v}}$ cells seem to be able to respond with period lengthening at moderate PDF levels $\left(s o^{l}\right)$ and with period shortening at high PDF levels $\left(s o^{m d a}\right)$ ?

Notably, the extra-PDF in the dorsal protocerebrum of $s o^{m d a}$ flies stems from misrouted l- $\mathrm{LN}_{\mathrm{v}}$ and not from the s- $\mathrm{LN}_{\mathrm{v}}$ cells that normally arborize in this brain area. In contrast to the s- $\mathrm{LN}_{\mathrm{v}}$, the l- $\mathrm{LN}_{\mathrm{v}}$ cells express the dimmed gene that leads to amidated PDF (Park et al., 2008). Amidated PDF is more active and has a longer half-life than nonamidated PDF. Little is known about the properties of the PDF receptor, but it is possible that the PDF receptor in the $\mathrm{DN}_{1 \mathrm{a}}$ or $\mathrm{DN}_{1 \mathrm{p} 1}$ gets saturated at certain PDF levels, and consequently other signaling pathways to the molecular clockwork overtake. For example, the $\mathrm{DN}_{1 \mathrm{a}}$ and $\mathrm{DN}_{1 \mathrm{p} 1}$ may get input from clock neurons that use other messengers. Good candidates are two of the three CRY-negative $\mathrm{LN}_{\mathrm{d}}$ that express Neuropeptide F (NPF), the homolog for the mammalian Neuropeptide Y (NPY) (Lee et al., 2006; Yoshii et al., 2008). NPY receptors mediate NPY action through coupling to G-proteins that downregulate the intracellular level of cAMP (Wen et al., 2005) and would thus counteract the PDF effect. The $\mathrm{DN}_{1 \mathrm{a}}$ or $\mathrm{DN}_{1 \mathrm{p} 1}$ that run now with short period may consecutively feedback on the $\mathrm{s}-\mathrm{LN}_{\mathrm{v}}$ and make them run also with shorter period (see supplemental Discussion, available at www.jneurosci.org as supplemental material). As a consequence, the short-period component appeared in the activity pattern.

Internal desynchronization into short- and long-period components was also found after electrical hyperexcitation of the $\mathrm{LN}_{\mathrm{v}}$ cells (Nitabach et al., 2006; Sheeba et al., 2008). The CRY-positive and CRY-negative $\mathrm{LN}_{\mathrm{d}}$ cells were not assessed separately in these studies; but the treatment provoked an internal desynchronization among the $\mathrm{DN}$ and between the fifth $s-\mathrm{LN}_{\mathrm{v}}$ and the $\mathrm{s}-\mathrm{LN}_{\mathrm{v}}$. Whereas the $\mathrm{s}-\mathrm{LN}_{\mathrm{v}}$ cells were associated with the short-period component in the present study, they were associated with the long-period component after hyperexcitation of the $\mathrm{LN}_{\mathrm{v}}$ cells (Sheeba et al., 2008). Obviously, the association of clock neurons with short- and longperiod components is variable and depends on environmental or intercellular signals. Together with the above-outlined putative interactions between different groups of clock neurons, this points to a flexible network of the clock. To understand the properties of the entire clock network, it will be necessary to reveal the physiological properties of single clock neurons as well as the interactions of all clock neurons (for review, see Nitabach and Taghert, 2008). Here, we propose a critical role of PDF in the network that can be tested in the future.

Under natural conditions, the role of PDF may be to keep the oscillations in the different subsets of clock neurons slightly out of phase. Different phases of clock neurons were also observed in the SCN (Quintero et al., 2003; Yamaguchi et al., 2003). This multiphasic SCN organization accounts for many properties of circadian organization, including the ability of the SCN to produce multiple-phase peak rhythms in vitro and in vivo (Jagota et al., 2000; Mrugala et al., 2000; Schwartz and Meijer, 2004) as well as to trigger various physiological output rhythms, and to respond to seasonal variations in the photoperiod by altering the coupling of its constituent oscillators (Pittendrigh and Daan, 1976). The same seems to apply for Drosophila (Grima et al., 2004; Shafer et al., 2004; Stoleru et al., 2004, 2005; Bachleitner et al., 2007; Fernández et al., 2007; Murad et al., 2007). We show here that $P d f^{01}$ mutants are unable to adapt their activity pattern to long photoperiods, indicating that PDF plays a major role in the seasonal adaptation of the clock.

\section{References}

Abrahamson EE, Moore RY (2001) Suprachiasmatic nucleus in the mouse; retinal innervation, intrinsic organization and efferent projections. Brain Res 916:172-191.

Aton SJ, Herzog ED (2005) Come together, right... now: synchronization of rhythms in a mammalian clock. Neuron 48:531-534.

Aton SJ, Colwell CS, Harmar AJ, Waschek J, Herzog ED (2005) Vasoactive intestinal polypeptide mediates circadian rhythmicity and synchrony in mammalian clock neurons. Nat Neurosci 8:476-483.

Bachleitner W, Kempinger L, Wülbeck C, Rieger D, Helfrich-Förster C (2007) Moonlight shifts the endogenous clock of Drosophila melanogaster. Proc Natl Acad Sci U S A 104:3538-3543.

Blanchardon E, Grima B, Klarsfeld A, Chélot E, Hardin PE, Préat T, Rouyer F (2001) Defining the role of Drosophila lateral neurons in the control of circadian rhythms in motor activity and eclosion by targeted genetic ablation and PERIOD protein overexpression. Eur J Neurosci 13:871-888.

de la Iglesia HO, Cambras T, Schwartz WJ, Díez-Noguera A (2004) Forced desynchronization of dual circadian oscillators within the rat suprachiasmatic nucleus. Curr Biol 14:796-800.

Fernández MP, Chu J, Villella A, Atkinson N, Kay SA, Ceriani MF (2007) Impaired clock output by altered connectivity in the circadian network. Proc Natl Acad Sci U S A 104:5650-5655.

Fischbach KF (1983) Neural cell types surviving congenital sensory deprivation in the optic lobes of Drosophila melanogaster. Dev Biol 95:1-18.

Foster RG, Roenneberg T (2008) Human responses to the geophysical daily, annual and lunar cycles. Curr Biol 18:R784-R794.

Grima B, Chélot E, Xia R, Rouyer F (2004) Morning and evening peaks of activity rely on different clock neurons of the Drosophila brain. Nature 431:869-873. 
Hardin PE (2005) The circadian timekeeping system of Drosophila. Curr Biol 15:R714-R722.

Helfrich-Förster C (1997) Development of pigment-dispersing hormoneimmunoreactive neurons in the nervous system of Drosophila melanogaster. J Comp Neurol 380:335-354.

Helfrich-Förster C (1998) Robust circadian rhythmicity of Drosophila melanogaster requires the presence of lateral neurons: a brain-behavioral study of disconnected mutants. J Comp Physiol A Neuroethol Sens Neural Behav Physiol 182:435-453.

Helfrich-Förster C (2005) Neurobiology of the fruit fly's circadian clock. Genes Brain Behav 4:65-76.

Helfrich-Förster C, Shafer OT, Wülbeck C, Grieshaber E, Rieger D, Taghert P (2007a) Development and morphology of the clock-gene-expressing lateral neurons of Drosophila melanogaster. J Comp Neurol 500:47-70.

Helfrich-Förster C, Yoshii T, Wülbeck C, Grieshaber E, Rieger D, Bachleitner W, Cusamano P, Rouyer F (2007b) The lateral and dorsal neurons of Drosophila melanogaster: new insights about their morphology and function. Cold Spring Harb Symp Quant Biol 72:517-525.

Hyun S, Lee Y, Hong ST, Bang S, Paik D, Kang J, Shin J, Lee J, Jeon K, Hwang S, Bae E, Kim J (2005) Drosophila GPCR Han is a receptor for the circadian clock neuropeptide PDF. Neuron 48:267-278.

Jagota A, de la Iglesia HO, Schwartz WJ (2000) Morning and evening circadian oscillations in the suprachiasmatic nucleus in vitro. Nat Neurosci 3:372-376.

Klarsfeld A, Malpel S, Michard-Vanhée C, Picot M, Chélot E, Rouyer F (2004) Novel features of cryptochrome-mediated photoreception in the brain circadian clock of Drosophila. J Neurosci 24:1468-1477.

Lear BC, Merrill CE, Lin JM, Schroeder A, Zhang L, Allada R (2005) A G protein-coupled receptor, groom-of-PDF, is required for PDF neuron action in circadian behavior. Neuron 48:221-227.

Lee G, Bahn JH, Park JH (2006) Sex and clock-controlled expression of the neuropeptide F gene in Drosophila. Proc Natl Acad Sci U S A 103:12580-12585.

Lin Y, Stormo GD, Taghert PH (2004) The neuropeptide pigmentdispersing factor coordinates pacemaker interactions in the Drosophila circadian system. J Neurosci 24:7951-7957.

Lowrey PL, Takahashi JS (2004) Mammalian circadian biology: elucidating genome-wide levels of temporal organization. Annu Rev Genomics Hum Genet 5:407-441.

Majercak J, Sidote D, Hardin PE, Edery I (1999) How a circadian clock adapts to seasonal decreases in temperature and day length. Neuron 24:219-230.

Maywood ES, Reddy AB, Wong GK, O’Neill JS, O’Brien JA, McMahon DG, Harmar AJ, Okamura H, Hastings MH (2006) Synchronization and maintenance of timekeeping in suprachiasmatic circadian clock cells by neuropeptidergic signaling. Curr Biol 16:599-605.

Mertens I, Vandingenen A, Johnson EC, Shafer OT, Li W, Trigg JS, De Loof A, Schoofs L, Taghert PH (2005) PDF receptor signaling in Drosophila contributes to both circadian and geotactic behaviors. Neuron 48:213-219.

Mrugala M, Zlomanczuk P, Jagota A, Schwartz WJ (2000) Rhythmic multiunit neural activity in slices of hamster suprachiasmatic nucleus reflect prior photoperiod. Am J Physiol Regul Integr Comp Physiol 278:R987-R994.

Murad A, Emery-Le M, Emery P (2007) A subset of dorsal neurons modulates circadian behavior and light responses in Drosophila. Neuron 53:689-701.

Nässel DR, Homberg U (2006) Neuropeptides in interneurons of the insect brain. Cell Tissue Res 326:1-24.

Nitabach MN, Taghert PH (2008) Organization of the Drosophila circadian control circuit. Curr Biol 18:R84-R93.

Nitabach MN, Wu Y, Sheeba V, Lemon WC, Strumbos J, Zelensky PK, White $\mathrm{BH}$, Holmes TC (2006) Electrical hyperexcitation of lateral ventral pacemaker neurons desynchronizes downstream circadian oscillators in the fly circadian circuit and induces multiple behavioral periods. J Neurosci 26:479-489.

Park D, Shafer OT, Shepherd SP, Suh H, Trigg JS, Taghert PH (2008) The Drosophila basic helix-loop-helix protein DIMMED directly activates $\mathrm{PHM}$, a gene encoding a neuropeptide-amidating enzyme. Mol Cell Biol 28:410-421.

Park JH, Helfrich-Förster C, Lee G, Liu L, Rosbash M, Hall JC (2000) Differential regulation of circadian pacemaker output by separate clock genes in Drosophila. Proc Natl Acad Sci U S A 97:3608-3613.
Peng Y, Stoleru D, Levine JD, Hall JC, Rosbash M (2003) Drosophila freerunning rhythms require intercellular communication. PLoS Biol 1:E13.

Petri B, Stengl M (1997) Pigment-dispersing hormone shifts the phase of the circadian pacemaker of the cockroach Leucophaea maderae. J Neurosci 17:4087-4093.

Petri B, Stengl M (2001) Phase response curves of a molecular model oscillator: implications for mutual coupling of paired oscillators. J Biol Rhythms 16:125-141.

Picot M, Cusumano P, Klarsfeld A, Ueda R, Rouyer F (2007) Light activates output from evening neurons and inhibits output from morning neurons in the Drosophila circadian clock. PLoS Biol 5:e315.

Piggins HD, Antle MC, Rusak B (1995) Neuropeptides phase shift the mammalian circadian pacemaker. J Neurosci 15:5612-5622.

Pittendrigh CS, Daan S (1976) A functional analysis of circadian pacemakers in nocturnal rodents. V. Pacemaker structure: a clock for all seasons. J Comp Physiol A Neuroethol Sens Neural Behav Physiol 106:333-355.

Plautz JD, Straume M, Stanewsky R, Jamison CF, Brandes C, Dowse HB, Hall JC, Kay SA (1997) Quantitative analysis of Drosophila period gene transcription in living animals. J Biol Rhythms 12:204-217.

Quintero JE, Kuhlman SJ, McMahon DG (2003) The biological clock nucleus: a multiphasic oscillator network regulated by light. J Neurosci 23:8070-8076.

Reed HE, Meyer-Spasche A, Cutler DJ, Coen CW, Piggins HD (2001) Vasoactive intestinal polypeptide (VIP) phase shifts the rat suprachiasmatic nucleus in vitro. Eur J Neurosci 13:839-843.

Renn SC, Park JH, Rosbash M, Hall JC, Taghert PH (1999) A Pdf neuropeptide gene mutation and ablation of PDF neurons each cause severe abnormalities of behavioral circadian rhythms in Drosophila. Cell 99:791-802.

Rieger D, Stanewsky R, Helfrich-Förster C (2003) Cryptochrome, compound eyes, Hofbauer-Buchner eyelets, and ocelli play different roles in the entrainment and masking pathway of the locomotor activity rhythm in the fruit fly Drosophila melanogaster. J Biol Rhythms 18:377-391.

Rieger D, Shafer OT, Tomioka K, Helfrich-Förster C (2006) Functional analysis of circadian pacemaker neurons in Drosophila melanogaster. J Neurosci 26:2531-2543.

Schneider NL, Stengl M (2005) Pigment-dispersing factor and GABA synchronize cells of the isolated circadian clock of the cockroach Leucophaea maderae. J Neurosci 25:5138-5147.

Schwartz WJ, Meijer JH (2004) Real-time imaging reveals spatiotemporal dynamics of cellular circadian clocks. Trends Neurosci 27:513-516.

Shafer OT, Rosbash M, Truman JW (2002) Sequential nuclear accumulation of the clock proteins period and timeless in the pacemaker neurons of Drosophila melanogaster. J Neurosci 22:5946-5954.

Shafer OT, Levine JD, Truman JW, Hall JC (2004) Flies by night: effects of changing day length on Drosophila's circadian clock. Curr Biol 14:424-432.

Shafer OT, Helfrich-Förster C, Renn SC, Taghert PH (2006) Reevaluation of Drosophila melanogaster's neuronal circadian pacemakers reveals new neuronal classes. J Comp Neurol 498:180-193.

Shafer OT, Kim DJ, Dunbar-Yaffe R, Nikolaev VO, Lohse MJ, Taghert PH (2008) Widespread receptivity to neuropeptide PDF throughout the neuronal circadian clock network of Drosophila revealed by realtime cyclic AMP imaging. Neuron 58:223-237.

Sheeba V, Sharma VK, Gu H, Chou YT, O’Dowd DK, Holmes TC (2008) Pigment dispersing factor-dependent and -independent circadian locomotor behavioral rhythms. J Neurosci 28:217-227.

Shinohara K, Honma S, Katsuno Y, Abe H, Honma K-I (1995) Two distinct oscillators in the rat suprachiasmatic nucleus in vitro. Proc Natl Acad Sci U S A 92:7396-7400.

Sidote D, Majercak J, Parikh V, Edery I (1998) Differential effects of light and heat on the Drosophila circadian clock proteins PER and TIM. Mol Cell Biol 18:2004-2013.

Stanewsky R, Frisch B, Brandes C, Hamblen-Coyle MJ, Rosbash M, Hall JC (1997) Temporal and spatial expression patterns of transgenes containing increasing amounts of the Drosophila clock gene period and a lacZ reporter: mapping elements of the PER protein involved in circadian cycling. J Neurosci 17:676-696.

Stoleru D, Peng Y, Agosto J, Rosbash M (2004) Coupled oscillators control morning and evening locomotor behaviour of Drosophila. Nature 431:862-868.

Stoleru D, Peng Y, Nawathean P, Rosbash M (2005) A resetting signal be- 
tween Drosophila pacemakers synchronizes morning and evening activity. Nature 438:238-242.

Stoleru D, Nawathean P, Fernández MP, Menet JS, Ceriani MF, Rosbash M (2007) The Drosophila circadian network is a seasonal timer. Cell 129:207-219.

Veleri S, Brandes C, Helfrich-Förster C, Hall JC, Stanewsky R (2003) A selfsustaining, light-entrainable circadian oscillator in the Drosophila brain. Curr Biol 13:1758-1767.

Vosko AM, Schroeder A, Loh DH, Colwell CS (2007) Vasoactive intestinal peptide and the mammalian circadian system. Gen Comp Endocrinol 152:165-175.

Wen T, Parrish CA, Xu D, Wu Q, Shen P (2005) Drosophila neuropeptide F and its receptor, NPFR1, define a signaling pathway that acutely modulates alcohol sensitivity. Proc Natl Acad Sci U S A 102:2142-2146.

Wu Y, Cao G, Nitabach MN (2008) Accelerated free-running cellular oscillation of non-LNv clock neurons in the absence of LNv electrical activity. J Biol Rhythms 23:117-128.
Wülbeck C, Grieshaber E, Helfrich-Förster C (2008) Pigment-dispersing factor (PDF) has different effects on Drosophila's circadian clocks in the accessory medulla and in the dorsal brain. J Biol Rhythms 23:409-424.

Yamaguchi S, Isejima H, Matsuo T, Okura R, Yagita K, Kobayashi M, Okamura H (2003) Synchronization of cellular clocks in the suprachiasmatic nucleus. Science 302:1408-1412.

Yang Z, Sehgal A (2001) Role of molecular oscillations in generating behavioral rhythms in Drosophila. Neuron 29:453-467.

Yoshii T, Funada Y, Ibuki-Ishibashi T, Matsumoto A, Tanimura T, Tomioka K (2004) Drosophila cry ${ }^{\mathrm{b}}$ mutation reveals two circadian clocks that drive locomotor rhythm and have different responsiveness to light. J Insect Physiol 50:479-488.

Yoshii T, Todo T, Wülbeck C, Stanewsky R, Helfrich-Förster C (2008) Cryptochrome is present in the compound eyes and a subset of Drosophila’s clock neurons. J Comp Neurol 508:952-966. 